\title{
Phosphorus-Containing Silsesquioxane Derivatives as Additive or Reactive Components of Epoxy Resins
}

\author{
Mariusz Szołyga ${ }^{1}$, Michał Dutkiewicz ${ }^{1,2}{ }^{1}$, Marek Nowicki ${ }^{1}$, Kamila Sałasińska ${ }^{3}{ }^{\circledR}$, \\ Maciej Celiński ${ }^{3}$ and Bogdan Marciniec ${ }^{1,4, *}$ \\ 1 Centre for Advanced Technologies, Adam Mickiewicz University in Poznan, Uniwersytetu Poznanskiego 10, \\ 61-614 Poznan, Poland; markussqueeze@wp.pl (M.S.); midu@amu.edu.pl (M.D.); \\ marek.nowicki@amu.edu.pl (M.N.) \\ 2 Poznan Science and Technology Park, Adam Mickiewicz University Foundation, Rubiez 46, 61-612 Poznan, Poland \\ 3 Department of Chemical, Biological and Aerosol Hazards, Central Institute for Labour Protection - National \\ Research Institute, Czerniakowska 16, 00-701 Warsaw, Poland; kasal@ciop.pl (K.S.); macel@ciop.pl (M.C.) \\ 4 Faculty of Chemistry, Adam Mickiewicz University in Poznan, Uniwersytetu Poznanskiego 8 , \\ 61-614 Poznan, Poland \\ * Correspondence: bogdan.marciniec@amu.edu.pl; Tel.: +48-61-8291988
}

Received: 3 November 2020; Accepted: 23 November 2020; Published: 26 November 2020

\begin{abstract}
Two phosphorus-containing cage-like silsesquioxane derivatives were synthesized as reactive or additive flame retardants for epoxy resin. The silsesquioxanes were obtained via an epoxide ring-opening reaction using a 10-hydroxy-9,10-dihydro-9-oxa-10-phosphaphenanthrene-10-oxide (DOPA). In one derivative containing in its structure 4 glycidoxypropyl and 4 phosphate groups, denoted as 4P4GS, only half of the epoxy rings was reacted with phosphate to obtain a reactive additive, while in the second derivative containing 8 phosphate groups, denoted as $8 \mathrm{PS}$, all epoxy groups were converted, thus an additive modifier was obtained. The ilsesquioxanes containing phosphorus atoms and the reactive phosphorus-free silsesquioxane derivative (octakis[(3-glycidoxypropyl)dimethylsiloxy]octasilsesquioxane (8GS)) were used to prepare hybrid materials based on epoxy resin. To compare the impact of the structure of silsesquioxane derivatives on the properties of hybrid materials, a number of samples containing 1,5 , and $10 \%$ of the modifiers making a series of epoxy materials containing additive or reactive modifiers, were obtained. The modified epoxies were studied using scanning electron microscopy and energy-dispersive X-ray spectroscopy (SEM-EDS), thermogravimetric analysis (TGA), differential scanning calorimetry (DSC), nanoindentation, water contact angle, and cone calorimetry tests to assess the effects of the modifier structure on the physicochemical properties of the investigated materials.
\end{abstract}

Keywords: silsesquioxane; phosphate; epoxy resin; flammability

\section{Introduction}

Epoxy resins are one of the most important and broadly explored chemo setting polymers containing reactive epoxy (oxirane) functional groups that are receptive to attack by both electrophiles and nucleophiles. This attractive feature has permitted the development of a wide group of compounds applied as hardeners of different reactivity (i.a., aliphatic and aromatic amines, carboxylic anhydrides) to enable obtaining systems crosslinking in a wide temperature range and showing various physicochemical properties [1-5]. Epoxy resins are vital in a very wide range of commercially important applications, from high strength adhesives and special coatings to advanced composites. Profound interest in these materials results from the desirable properties of the hardened resin, including good adhesion to many surfaces, rather high hardness (often resulting from the type of 
modifier used), good resistance to external factors (chemical and environmental), high electrical resistance, and low shrinkage, as well as the possibility of the adaptation of the curing reaction to suit the processing requirements [6-9]. Unfortunately, one of the greatest limitations in the use of epoxy resins is their relatively high flammability and low thermal stability $[10,11]$. To circumvent these disadvantages, several flame-retardant additives have been applied in commercially available epoxy resins, including phosphorus compounds (e.g., triphenylphosphine, tris- $\beta$-chloroethyl phosphate), hydrates (e.g., alumina trihydrate), halogenated compounds (e.g., octabromobiphenyl, decabromobiphenyl, dechlorane) in different amounts ranging from 5 to $30 \%$, often together with synergists like antimony oxide, zinc borate, or molybdic oxide [12-14].

Irrespective of the chemical structure and flame retardancy mechanism, flame retardants (FRs) can be divided into two groups: additive and reactive. The first of them is physically incorporated into the polymer matrix during its processing and does not react chemically with the polymer. The other ones are commonly introduced into the polymer at the stage of its synthesis (as co-monomers or polymer precursors) or in a polymer fictionalization process (polymer grafting). The latter FRs are chemically bonded to the modified polymers in this way [15]. The most commonly used FRs were based on halogenated organic derivatives. However, the presence of the halogen atoms (chlorine or bromine) in their structure caused the evolution of toxic and corrosive gases during the combustion of modified materials [16]. For this reason, the search for new FRs is still a top priority. Particularly promising are the materials based on silicon-, phosphorus-, and boron-containing compounds [17-20]. Moreover, besides the use of the abovementioned synergists, the literature also confirms the synergy of phosphorus and silicon compounds combined into one material [21,22]. Recently, the combination of additive phosphorus FRs and silsesquioxane derivatives have attracted the attention of several research groups [23-27].

In their work, Shi et al. describe the simultaneous modification of epoxy resin with octaaminophenyl silsesquioxanes and polyphosphazene, resulting in the formation of flame-retardant composites with significantly reduced peak heat release rate (pHRR) values [23]. A similar synergistic effect of silicon and phosphorus was reported by Cakmakci [24]. In his work, allylaminodiphenylphosphine oxide (APA) and octamercaptopropyl silsesquioxane were used to improve the flame retardancy of photocured epoxy acrylate-based coatings. The addition of APA itself influenced the reduction of the obtained epoxy acrylate composites' flammability, while the addition of only silsesquioxane to the system increased their flammability [24]. In the work of Zhang et al., the pyrolysis and fire behavior of epoxy resin composites based on a silsesquioxane resin containing 9,10-dihydro-9-oxa-10-phosphaphenanthrene-10-oxide (DOPO-POSS) and diglycidyl ether of bisphenol A (DGEBA) were investigated. The results of the cone calorimetry measurements indicated that DOPO-POSS can significantly reduce the HRR of the investigated materials and enhance the formation of a char yield [25]. In their work, Zhang et al. described the effects of the phosphorus-based flame retardants applied with or without octaphenyl silsesquioxane (OPS) on the flammability of the prepared materials. The results of the LOI (limiting oxygen index) and UL-94 (flammability standard released by Underwriters Laboratories) tests showed that the flame retardancy of the samples is defined by the chemical structure of phosphorus FRs; however, the addition of OPS could enhance these effects [26]. In their work, Wang et al. also described the behavior of epoxy resin/silsesquioxane hybrids and phosphorus-silicon synergism, which improved the flame retardancy of the investigated systems. They have concluded that phosphorus promoted the char formation, while silicon protected the char against its thermal degradation [27].

However, cage-like silsesquioxanes containing other flame-retardant atoms, such as phosphorus or boron, incorporated into their structure have not been used and the relationship between the modifier structure and thermal stability or flammability of epoxy resins have not been evaluated as yet. Therefore, we decided to synthesize a family of phosphorus-containing cage-like silsesquioxane derivatives bearing different numbers of epoxy and phosphate groups to be used as reactive or additive epoxy resin modifiers. Subsequently, the proposed derivatives were used for epoxy resin modification, 
and the prepared materials were subjected to a series of tests to determine the influence of the structure of the proposed derivatives and the manner of their interaction with the polymer matrix on the properties of the obtained materials.

\section{Materials and Methods}

\subsection{Materials}

Octakis(hydridodimethylsiloxy)octasilsesquioxane was supplied by PIW Unisil Sp. z o.o., Tarnów, Poland, and 9,10-dihydro-9-oxa-10-phosphahenanthrene-10-oxide (DOPO) (>97\%) was purchased from TCI Deutschland GmbH, Eschborn, Germany. Chloroform-d, allyl glycidyl ether ( $\geq 99 \%$ ), and Karstedt catalyst (2\% Pt in xylenes) were purchased from Sigma-Aldrich Sp. z o.o, Poznań, Poland. Acetone, tetrahydrofuran (THF), and toluene (all purities were suitable for analysis) were purchased from POCH, Gliwice, Poland. Hydrogen peroxide (30\%) was purchased from ChemPur, Piekary Ślaskie, Poland. Epoxy resin Epidian 652 (E652) and isophoronediamine (IDA) as a hardener were purchased from Ciech Resins, Nowa Sarzyna, Poland. All reagents were used without further purification.

\subsection{Analytical Techniques}

\subsubsection{Nuclear Magnetic Resonance Spectroscopy (NMR)}

${ }^{1} \mathrm{H},{ }^{13} \mathrm{C},{ }^{29} \mathrm{Si}$, and ${ }^{31} \mathrm{P}$ NMR spectra were recorded on a Varian XL 300, Zug, Switzerland, spectrometer at room temperature using $\mathrm{CDCl}_{3}$ as a solvent.

\subsubsection{Infrared Spectroscopy (FT-IR)}

FT-IR spectra were recorded on a Bruker Tensor 27, Billerica, MA, USA, Fourier-transform spectrophotometer equipped with a single-reflection diamond ATR (Attenuated Total Reflectance) SPECAC Golden Gate, Orpington, GB module. In all cases, 16 scans were collected at a resolution of $2 \mathrm{~cm}^{-1}$ for the spectrum.

\subsubsection{Thermogravimetric Analysis (TGA)}

Thermogravimetric analysis was carried out using a Mettler Toledo TGA/DSC 1 STAR ${ }^{\mathrm{e}}$ System Columbus, $\mathrm{OH}, \mathrm{USA}$. The measurements were conducted in an air or $\mathrm{N}_{2}$ atmosphere at a flow rate of $60 \mathrm{~mL} \mathrm{~min}^{-1}$, in the temperature range from room temperature (RT) to $800^{\circ} \mathrm{C}$ at a heating rate of $10 \mathrm{~K} \mathrm{~min}^{-1}$.

\subsubsection{Scanning Electron Microscope and Energy-Dispersive X-ray Spectroscopy (SEM, EDS)}

The epoxy resin composites' morphology was defined based on SEM images using an FEI Quanta 250 FEG, Hillsboro, Oregon, USA, field emission scanning electron microscope equipped with an EDAX, Mahwah, NJ, USA EDS (Energy Dispersive Spectroscopy) detector. The measurements were carried out in low- or high-vacuum mode. In the low-vacuum mode (50-100 Pa) with a $10 \mathrm{kV}$ accelerating voltage, the signal was collected by an LFD (Low vacuum Secondary Electron) detector, while in the high-vacuum mode $\left(2.5 \times 10^{-4} \mathrm{~Pa}\right)$, the accelerating voltage was $5 \mathrm{kV}$ and the signal was collected by an ETD (Everhart-Thornley Detector) FEI, Hillsboro, Oregon, USA, detector.

\subsubsection{Differential Scanning Calorimetry (DSC)}

DSC measurements were carried out using a Mettler Toledo DSC-1, Columbus, OH, USA, differential scanning calorimeter. Each prepared epoxy resin composite sample was placed in $40 \mu \mathrm{L}$ aluminum pans with a pierced lid and analyzed in a $\mathrm{N}_{2}$ atmosphere at a flow rate of $25 \mathrm{~mL} \mathrm{~min}^{-1}$ in the temperature range from 25 to $230{ }^{\circ} \mathrm{C}$ at a heating/cooling rate of $10 \mathrm{~K} \mathrm{~min}^{-1}$ to establish its glass transition temperature $\left(\mathrm{T}_{\mathrm{g}}\right)$. The $\mathrm{T}_{\mathrm{g}}$ temperatures were assessed as the midpoints of the characteristic step transition in the baseline of the second cooling curves. 


\subsubsection{Cone Calorimetry}

The flammability of the prepared composites was assessed based on the results of cone calorimetry measurements. All samples were tested using Fire Testing Technology Ltd., East Grinstead, UK, apparatus according to ISO 5660 standard. Samples of dimensions of $100 \times 100 \times 6 \mathrm{~mm}$ were placed in aluminum foil and irradiated horizontally at a heat flux of $35 \mathrm{~kW} \mathrm{~m}^{-2}$. The pyrolysis products that were released during tests were spark ignited. The images of the residues after the flammability tests were collected using a Canon Inc. EOS 400 D Tokyo, Japan, digital camera. The FIGRA (fire growth rate) was calculated based on Equation (1):

$$
\text { FIGRA }=\frac{\mathrm{pHRR}}{\mathrm{T}_{\mathrm{pHRR}}},
$$

where $\mathrm{pHRR}$ is the maximum heat release rate and $\mathrm{T}_{\mathrm{pHRR}}$ is the time of the $\mathrm{pHRR}$ occurrences.

\subsubsection{Nanomechanical Analysis}

The hardness and modulus of elasticity of the prepared samples were measured using a nanoindentation technique on an Agilent 5500 Santa Clara, CA, USA indenter with a high-precision DCM (Dynamic Contact Module) measuring head. A fused quartz sample was used for the nanoindenter calibration. The hardness and modulus of elasticity were calculated on the basis of results averaged from five measuring points for each sample.

\subsubsection{Static Water Contact Angle (WCA)}

Static WCA values were measured using a Krüss GmbH DSA 100 Expert, Hamburg, Germany, drop shape analyzer equipped with a software-controlled (DSA4 2.0 Hamburg, Germany) motorized samples table, automatic dosing unit with automatically adjusted zoom, focus, illumination, and a camera with a $780 \times 580$ pix resolution. The drop profile was extracted using a circle-fitting model. Presented data are arithmetic means of measurements for five drops ( $5 \mu \mathrm{L}$ volume) per sample.

\subsection{Synthetic Procedures}

\subsubsection{Synthesis of Octakis[(3-glycidoxypropyl)dimethylsiloxy]octasilsesquioxane (8GS)}

8GS was synthesized according to the procedure described previously by authors via the hydrosilylation of allyl-glycidyl ether with octakisdimethylsiloxyoctasilsesquioxane catalyzed using Karstedt's complex [19]. Dry toluene (400 mL) as a solvent, octakisdimethylsiloxyoctasilsesquioxane ( $40 \mathrm{~g}, 39.2 \mathrm{mmol})$, and allyl-glycidyl ether $(44.8 \mathrm{~mL}, 376 \mathrm{mmol}$ with $20 \%$ excess) were placed together in a reactor equipped with a thermometer, a condenser, and a magnetic bar. Next, Karstedt catalyst $\left(171.2 \mathrm{mg}, 2.35 \times 10^{-6} \mathrm{~mol} \mathrm{Pt}\right)$ was added at RT and the reaction mixture was heated to $110^{\circ} \mathrm{C}$ and stirred for $8 \mathrm{~h}$. After the reaction mixture had cooled down, the excess of olefin and the solvent were evaporated under vacuum to give a product as a viscous oil.

Spectroscopic analysis for 8GS: ${ }^{1} \mathrm{H}$ NMR $\left(\mathrm{CDCl}_{3}, \delta(\mathrm{ppm})\right)$ : $0.12\left(\mathrm{OSiCH}_{3}\right) ; 0.58\left(\mathrm{SiCH}_{2}\right) ; 1.60$ $\left(\mathrm{CH}_{2}\right) ; 2.57,2.76\left(\mathrm{CH}_{2} \mathrm{O}\right) ; 3.11(\mathrm{CHO}) ; 3.36\left(\mathrm{CH}_{2} \mathrm{O}\right) ; 3.43$, $3.66\left(\mathrm{OCH}_{2}\right) .{ }^{13} \mathrm{C} \mathrm{NMR}\left(\mathrm{CDCl}_{3}, \delta(\mathrm{ppm})\right)$ : $-0.30\left(\mathrm{SiCH}_{3}\right) ; 13.75\left(\mathrm{SiCH}_{2}\right) ; 23.26\left(\mathrm{CH}_{2}\right) ; 44.38\left(\mathrm{CH}_{2} \mathrm{O}\right) ; 50.91(\mathrm{CHO}) ; 71.53\left(\mathrm{OCH}_{2}\right) ; 74.17\left(\mathrm{CH}_{2} \mathrm{O}\right)$.

${ }^{29} \mathrm{Si} \mathrm{NMR}\left(\mathrm{CDCl}_{3}, \delta(\mathrm{ppm})\right): 12.90\left(\mathrm{OSi}\left(\mathrm{CH}_{3}\right)_{2}\right) ;-109.10$ (SiOSi). FT-IR (ATR): 2998-2955, 2931, 2869, $1253,1070,902,838 \mathrm{~cm}^{-1}$.

\subsubsection{Synthesis of 10-Hydroxy-9,10-dihydro-9-oxa-10-phosphaphenanthrene-10-oxide (DOPA)}

DOPA was synthesized according to the procedure described elsewhere with a slight modification [28]. 9,10-Dihydro-9-oxa-10-phosphahenanthrene-10-oxide (50 g, $230 \mathrm{mmol}$ ) was placed in a three-necked round-bottom flask equipped with a thermometer, a condenser, and a magnetic bar, and hydrogen peroxide $(150 \mathrm{~mL}, 1.9 \mathrm{~mol})$ was added in one portion at room temperature. The 
temperature of the reaction mixture gradually rose to $100{ }^{\circ} \mathrm{C}$ and was allowed to drop down to $80^{\circ} \mathrm{C}$. The reaction mixture was stirred at this temperature overnight, cooled down to room temperature, and filtered. The obtained product was washed with acetone several times and dried overnight at $80^{\circ} \mathrm{C}$.

Spectroscopic analysis for DOPA: ${ }^{1} \mathrm{H}$ NMR $\left(\mathrm{CDCl}_{3}, \delta(\mathrm{ppm})\right)$ : $3.73(\mathrm{PO}-\mathrm{H}) ; 7.28-8.10\left(\mathrm{C}-\mathrm{H}_{\mathrm{ar}}\right)$. ${ }^{13} \mathrm{C} \mathrm{NMR}\left(\mathrm{CDCl}_{3}, \delta(\mathrm{ppm})\right): 120.45-133.33\left(\mathrm{C}-\mathrm{H}_{\mathrm{ar}}\right) .{ }^{31} \mathrm{P} \mathrm{NMR}\left(\mathrm{CDCl}_{3}, \delta(\mathrm{ppm})\right): 14.03$. FT-IR (ATR): 3100-3000, 1650-1450, 1210, 1000-920 cm $\mathrm{cm}^{-1}$. Substrate and product structures (DOPO and DOPA) as well as FT-IR and NMR spectra of DOPA presented in Figures S1-S5 are available in Supplementary Materials.

\subsubsection{Synthesis of Phosphorus-Containing Silsesquioxanes (4P4GS and 8PS)}

A dry $250 \mathrm{~mL}$ three-necked flask equipped with a magnetic stirrer, thermometer, and reflux condenser was loaded with $10 \mathrm{~g}(5.2 \mathrm{mmol})$ of 8GS, $4.81 \mathrm{~g}(20.7 \mathrm{mmol})$ of DOPA (for the synthesis of 4 P4GS and $9.62 \mathrm{~g}$ (41.4 mmol) for the synthesis of 8PS), and $100 \mathrm{~mL}$ of THF. The flask was then placed in an oil bath and the solution was heated to $55^{\circ} \mathrm{C}$ and vigorously stirred. After about $3 \mathrm{~h}$, the DOPA precipitate disappeared and the solution became transparent. The reaction was continued for another $20 \mathrm{~h}$. After this time, the solution was transferred to a single-neck flask and the volatile components were evaporated on a vacuum evaporator. The product was then dried for another $48 \mathrm{~h}$ using a vacuum pump. The obtained products were in the form of a light orange, highly viscous oil. The reaction yield was quantitative (product weight for 4P4GS was $14.8 \mathrm{~g}$ and for 8PS was $19.6 \mathrm{~g}$ ).

Spectroscopic analysis for 4P4GS: ${ }^{1} \mathrm{H}$ NMR $\left(\mathrm{CDCl}_{3}, \delta(\mathrm{ppm})\right): 0.09,0.10\left(\mathrm{OSiCH}_{3}\right) ; 0.56\left(\mathrm{SiCH}_{2}\right)$; $1.58\left(\mathrm{CH}_{2}\right) ; 2.55,2.73\left(\mathrm{CH}_{2} \mathrm{O}\right) ; 3.09(\mathrm{CHO}) ; 3.09-3.64\left(\mathrm{CH}_{2} \mathrm{OH}, \mathrm{CHOH}, \mathrm{CH}_{2} \mathrm{O}\right) ; 3.87(\mathrm{HCOH}) ; 4.12$ $\left(\mathrm{CH}_{2} \mathrm{OH}\right) ; 7.20-7.90\left(\mathrm{C}-\mathrm{H}_{\mathrm{ar}}\right) .{ }^{13} \mathrm{C} \mathrm{NMR}\left(\mathrm{CDCl}_{3}, \delta(\mathrm{ppm})\right):-0.35\left(\mathrm{SiCH}_{3}\right) ; 13.67\left(\mathrm{SiCH}_{2}\right) ; 23.10\left(\mathrm{CH}_{2}\right)$; $44.28\left(\mathrm{CH}_{2} \mathrm{O}\right) ; 50.88(\mathrm{CHO}) ; 59.18-74.14\left(\mathrm{CH}_{2} \mathrm{O}, \mathrm{CHOH}\right.$, and $\left.\mathrm{CH}_{2} \mathrm{OH}\right) ; 120.26-137.00$ and $149.81\left(\mathrm{C}_{\mathrm{ar}}\right)$. ${ }^{29} \mathrm{Si} \mathrm{NMR}\left(\mathrm{CDCl}_{3}, \delta(\mathrm{ppm})\right): 12.97\left(\mathrm{OSi}\left(\mathrm{CH}_{3}\right)_{2}\right) ;-109.04(\mathrm{SiOSi}) .{ }^{31} \mathrm{P} \mathrm{NMR}\left(\mathrm{CDCl}_{3}, \delta(\mathrm{ppm})\right): 11.28$ (P-O-C $)$; 10.19 (P-O-C ${ }^{\mathrm{II}}$ ). FT-IR (ATR): 3600-3200, 3100-3000, 2998, 2955, 2931, 2869, 1650-1450, 1253, $1210,1070,902,838 \mathrm{~cm}^{-1}$.

Spectroscopic analysis for 8PS: ${ }^{1} \mathrm{H} \mathrm{NMR}\left(\mathrm{CDCl}_{3}, \delta(\mathrm{ppm})\right): 0.08\left(\mathrm{OSiCH}_{3}\right) ; 0.49\left(\mathrm{SiCH}_{2}\right) ; 1.50$ $\left(\mathrm{CH}_{2}\right) ; 3.32\left(\mathrm{CH}_{2} \mathrm{OH}, \mathrm{CHOH}, \mathrm{CH}_{2} \mathrm{O}\right) ; 3.88(\underline{\mathrm{HCOH}}) ; 4.14\left(\underline{\mathrm{CH}}_{2} \mathrm{OH}\right) ; 7.19-7.88\left(\mathrm{C}-\mathrm{H}_{\mathrm{ar}}\right) .{ }^{13} \mathrm{C} \mathrm{NMR}$ $\left(\mathrm{CDCl}_{3}, \delta(\mathrm{ppm})\right):-0.33\left(\mathrm{SiCH}_{3}\right) ; 13.60\left(\mathrm{SiCH}_{2}\right) ; 23.02\left(\mathrm{CH}_{2}\right) ; 59.19-74.13\left(\mathrm{CH}_{2} \mathrm{O}, \mathrm{CHOH}\right.$ and $\left.\mathrm{CH}_{2} \mathrm{OH}\right)$; 120.19-136.99 and $149.78\left(\mathrm{C}_{\mathrm{ar}}\right) .{ }^{29} \mathrm{Si} \mathrm{NMR}\left(\mathrm{CDCl}_{3}, \delta(\mathrm{ppm})\right): 13.00\left(\mathrm{OSi}\left(\mathrm{CH}_{3}\right)_{2}\right) ;-109.02(\mathrm{SiOSi}) .{ }^{31} \mathrm{P}$ NMR $\left(\mathrm{CDCl}_{3}, \delta(\mathrm{ppm})\right): 11.14\left(\mathrm{P}-\mathrm{O}-\mathrm{C}^{\mathrm{I}}\right) ; 10.23$ (P-O-C $\left.{ }^{\mathrm{II}}\right)$. FT-IR (ATR): 3600-3200, 3100-3000, 2998, $2955,2931,2869,1650-1450,1253,1210,1070,902,838 \mathrm{~cm}^{-1}$.

\subsubsection{Epoxy Resin Samples Preparation}

The appropriate amount $(1,5$, or $10 \%$ ) of the modifier (silsesquioxane 8 GS, 4P4GS, or 8PS) was weighed into a plastic cup (amounts given in Table 1). Then, $40 \mathrm{~g}$ of epoxy resin (Epidian 652) was added to the cup and the contents were vigorously stirred by hand with a wooden stick for 10 min until the mixture was fully homogeneous. In a second cup, the appropriate amount of isophoronediamine (IDA) as a hardener (the amounts of hardener given in Table 1 were calculated such that it would react the epoxy groups present in both Epidian 652 and silsesquioxane) was weighed and poured into the cup already containing the resin with the modifier, and then the contents were vigorously stirred. Then, the resulting mixture was transferred to the hardener cup and stirred again, then poured into the resin cup again, and stirred (this procedure was repeated three times). 
Table 1. Epoxy resin samples' compositions.

\begin{tabular}{|c|c|c|c|c|}
\hline Sample & E $652(\mathrm{~g})$ & IDA (g) & Modifier & Modifier Mass (g) \\
\hline Ref. & & 20 & - & - \\
\hline $1 \%-8 \mathrm{GS}$ & & 20.166 & 8GS & 0.4 \\
\hline $5 \%-8 G S$ & & 20.828 & $8 G S$ & 2 \\
\hline $10 \%-8 \mathrm{GS}$ & 40 & 21.656 & 8GS & 4 \\
\hline 1\%-4P4GS & & 20.056 & 4P4GS & 0.4 \\
\hline $5 \%-4 \mathrm{P} 4 \mathrm{GS}$ & & 20.28 & 4P4GS & 2 \\
\hline $10 \%-4 \mathrm{P} 4 \mathrm{GS}$ & & 20.56 & 4P4GS & 4 \\
\hline $1 \%-8 \mathrm{PS}$ & & 20 & 8PS & 0.4 \\
\hline $5 \%-8 P S$ & & 20 & 8PS & 2 \\
\hline $10 \%-8 \mathrm{PS}$ & & 20 & 8PS & 4 \\
\hline
\end{tabular}

The mixture obtained in this way was divided into three parts placed in a $10 \times 10 \times 0.6 \mathrm{~cm}$ mold, on a glass plate $(2.6 \times 7.5 \mathrm{~cm})$, and in a cylindrical form (diameter of $1.1 \mathrm{~cm}$ and height of $0.8 \mathrm{~cm}$ ). Air bubbles were removed using a gas burner. The samples were left for 2 weeks at ambient temperature to fully cure.

\section{Results and Discussion}

\subsection{Silsesquioxanes Synthesis and Characterization}

The first step toward the implementation of the planned scope of research, assuming the assessment of the impact of the structure of silsesquioxane derivatives containing phosphate groups on the modified epoxy resins' flammability, was the synthesis of appropriate derivatives.

According to the presented Scheme 1, the synthesis was conducted in two steps. In the first one, the 8GS derivative containing eight glycidoxypropyl groups was obtained via hydrosilylation of the allyl-glycidyl ether with octakisdimethylsiloxyoctasilsesquioxane catalyzed using Karstedt's complex, and after isolation, it was used as a substrate for the synthesis of two further derivatives. The synthesis of the 4P4GS derivative containing four glycidoxypropyl and four phosphate groups and the 8PS one containing eight phosphate groups only was carried out via an epoxy ring-opening reaction using the 8GS derivative and DOPA as substrates. By changing the stoichiometry of the reagents used, the silsesquioxane derivatives that could act as reactive flame retardants (4P4GS) chemically bonded to the structure of the modified epoxy resin or as an additive (8PS) that only physically mixed with the polymer matrix were prepared. Subsequently, the obtained derivatives were subjected to the spectroscopic analyses $\left({ }^{1} \mathrm{H}-,{ }^{13} \mathrm{C}-,{ }^{29} \mathrm{Si}-,{ }^{31} \mathrm{P}-\mathrm{NMR}\right.$, and FT-IR), which confirmed their structures. As can be observed in Figure 1, which shows the stacked ${ }^{1} \mathrm{H}$ NMR, in the spectra of the 8GS, 4P4GS, and $8 \mathrm{PS}$ derivatives, the signals from the protons present in the $\mathrm{Si}\left(\mathrm{CH}_{3}\right)_{2}$ groups at $0.12 \mathrm{ppm}$ and $\mathrm{CH}_{2}$ groups of alkyl chains at 0.58 and $1.6 \mathrm{ppm}$ in the spectrum of the 8GS derivative were broadened and shifted upfield in the spectra of the 4P4GS and 8PS derivatives. The intensity of the signals from the protons of the ether and epoxy groups present in the spectrum of the 8GS derivative at 2.57, 2.76, 3.11, and $3.66 \mathrm{ppm}$ decreased in the spectrum of the 4P4GS derivative and disappeared completely in the spectrum of the 8PS derivative. At the same time, the formation of new signals in the spectra of 4P4GS and $8 \mathrm{PS}$ derivatives at 3.88 and $4.13 \mathrm{ppm}$ as a result of the epoxy ring-opening of $8 \mathrm{GS}$ derivatives is observed. Furthermore, the spectra of the 4P4GS and 8PS derivatives also showed groups of signals ranging from 7.1 to $8 \mathrm{ppm}$ that are characteristic of the protons of aromatic groups derived from the 
DOPA derivative. NMR spectra of all discussed silsesquioxane derivatives are presented in Figures S6-S16 available in Supplementary Materials.

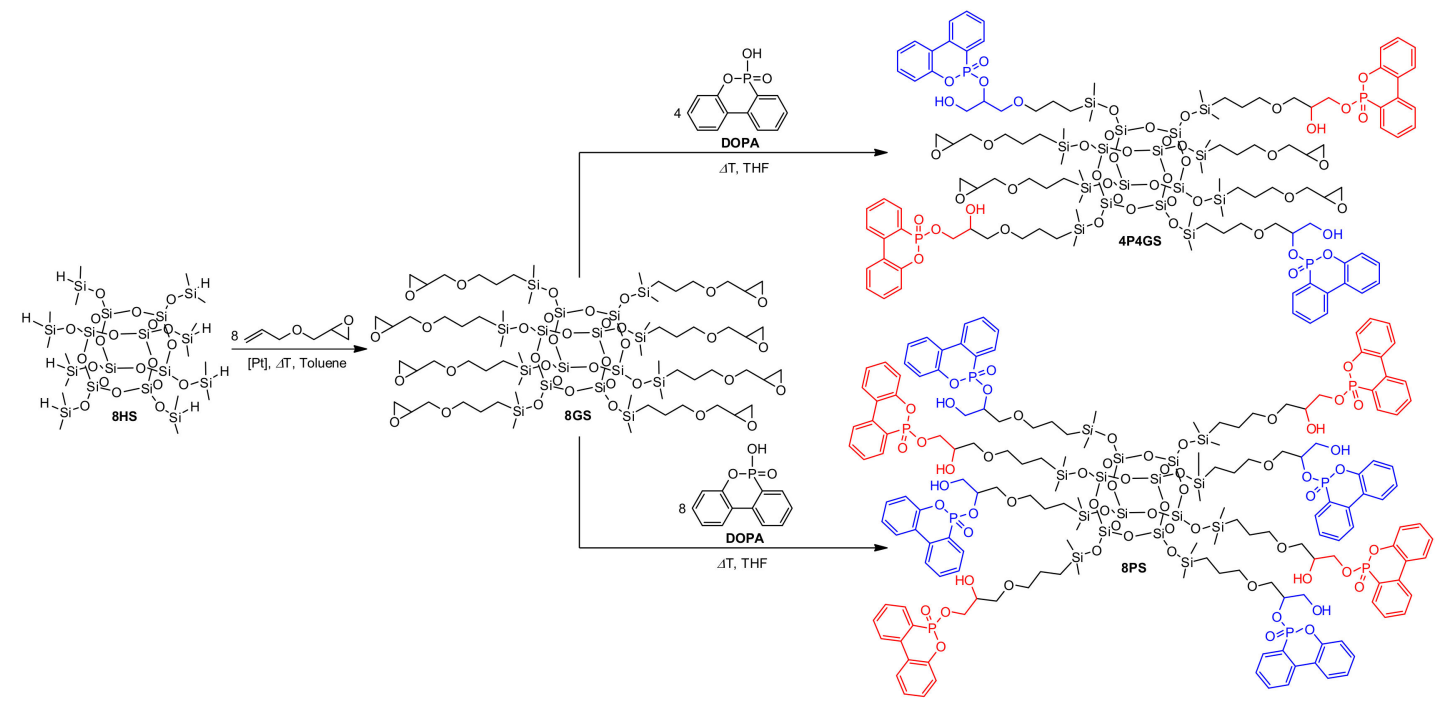

Scheme 1. Synthesis of 8GS, 4P4GS, and 8PS silsesquioxane derivatives. 8HS: octakis(dimethylsiloksyhydrido)octasilsesquioxane, DOPA: 10-hydroxy-9,10-dihydro-9-oxa-10phosphaphenanthrene-10-oxide,THF: tetrahydrofuran.

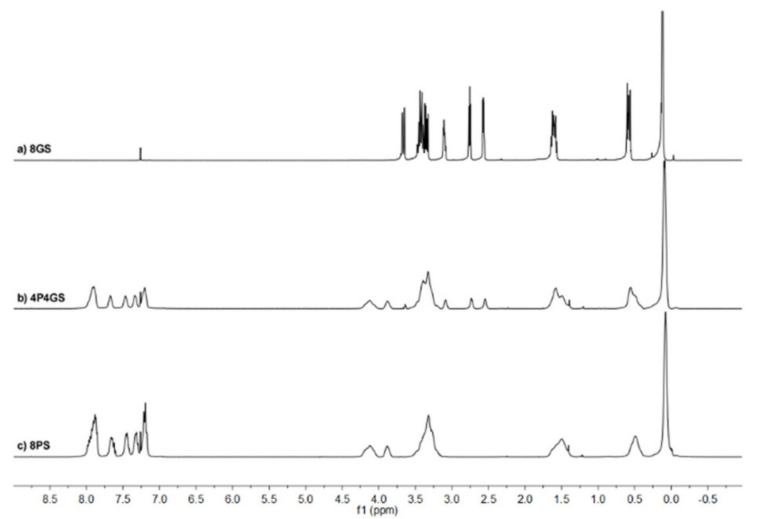

Figure 1. Stacked ${ }^{1} \mathrm{H}$ nuclear magnetic resonance (NMR) spectra of the (a) 8GS, (b) 4P4GS, and (c) 8PS derivatives.

However, it needs to be highlighted that the structures of the obtained compounds (4P4GS and 8PS) presented in Scheme 1 are a kind of simplification. The applied method for the synthesis of the 4P4GS derivative containing phosphate and glycidoxypropyl groups in its structure leads, in fact, to the formation of a mixture of compounds with different numbers of the discussed groups and their different arrangements around the inorganic silsesquioxane core, which was demonstrated in the earlier works of our research group based on the results of the MALDI (Assisted Laser Desorption and Ionization (UltrafleXtreme, Bruker, Billerica, MA, USA)) analysis of silsesquioxane derivatives containing two types of functional groups in their structures [29,30]. However, statistically, the ratio of epoxy to phosphate groups was 4:4. In the case of the 8PS derivative, the presence of a mixture of compounds should also be assumed, which resulted from the possibility of a different substitution of DOPA to epoxy groups, as shown in Scheme 1.

Furthermore, the results of the FT-IR analysis of the obtained derivatives presented in Figure 2 confirmed the structures of the obtained derivatives. This was evidenced by the appearance of bands that are characteristic for vibrations of $\mathrm{OH}$ groups at $3400 \mathrm{~cm}^{-1}$ in the spectra of 4P4GS and 8PS 
derivatives, groups of bands in the range of $1600-1400 \mathrm{~cm}^{-1}$, and bands with a maximum at 1070 (split), 905, and $754 \mathrm{~cm}^{-1}$, which were assigned to the stretching vibrations of $\mathrm{C}-\mathrm{H}$ and $\mathrm{C}=\mathrm{C}$ bonds of aromatic rings, stretching vibrations of $\mathrm{P}-\mathrm{C}$ (aromatic) bonds, and asymmetric and symmetric stretching vibrations of $\mathrm{P}-\mathrm{O}-\mathrm{C}$ (aliphatic) bonds, respectively.

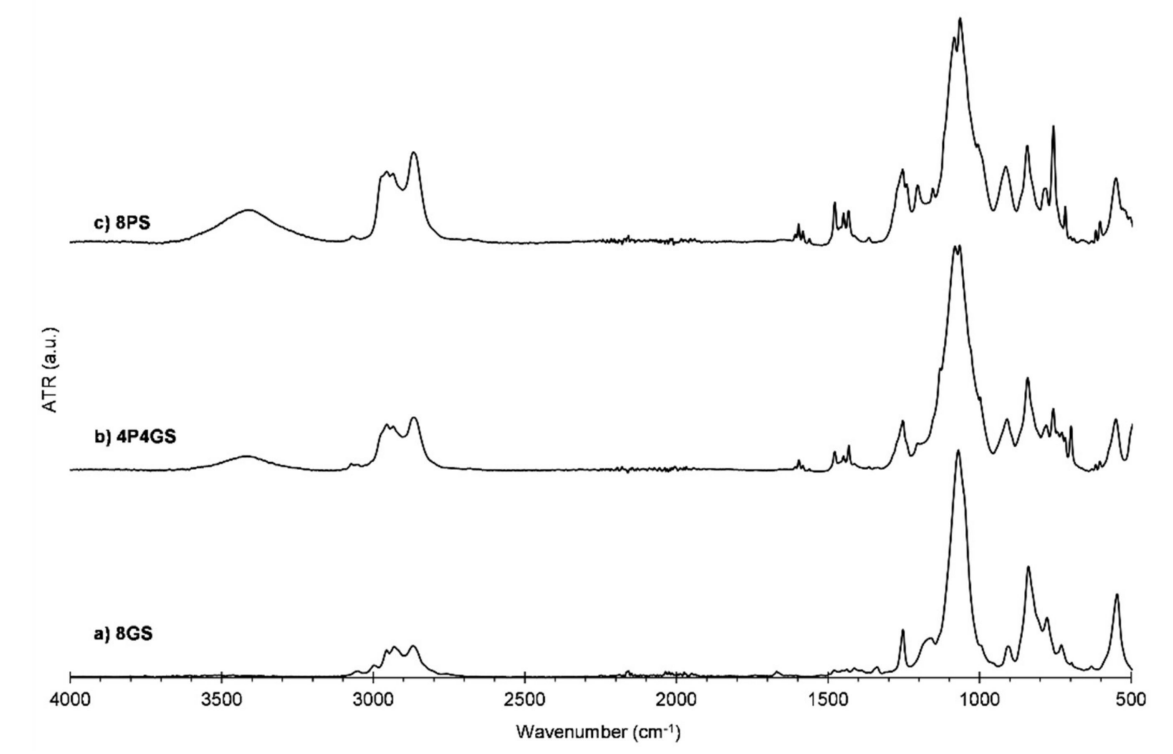

Figure 2. Stacked Fourier-transform infrared spectroscopy (FT-IR) spectra of the (a) 8GS, (b) 4P4GS, and (c) 8PS derivatives.

The obtained silsesquioxane derivatives were then used to prepare samples of modified epoxy resins based on the isophoronediamine-cured Epidian 652 resin, as described in Section 2.3.4. The resin samples prepared in this way were subjected to further tests to assess the effect of the structure and amount of used modifiers on the properties of the produced resins.

\subsection{Scanning Electron Microscopy and Energy-Dispersive X-ray Spectroscopy Measurements}

The SEM technique combined with EDS was employed for the evaluation of the amount and the distribution of silsesquioxane modifiers used in the epoxy matrix based on the silicon and phosphorous atoms' concentrations. Analysis of the recorded images confirmed the uniform distribution of modifiers in the polymer matrix, irrespective of the type and amount of the modifier used, as shown in the exemplary distribution maps of silicon atoms in the samples $10 \%-8 \mathrm{GS}, 10 \%-4 \mathrm{P} 4 \mathrm{GS}$, and $10 \%-8 \mathrm{PS}$, which contained the highest amounts of each modifier used, as presented in Figure 3. 

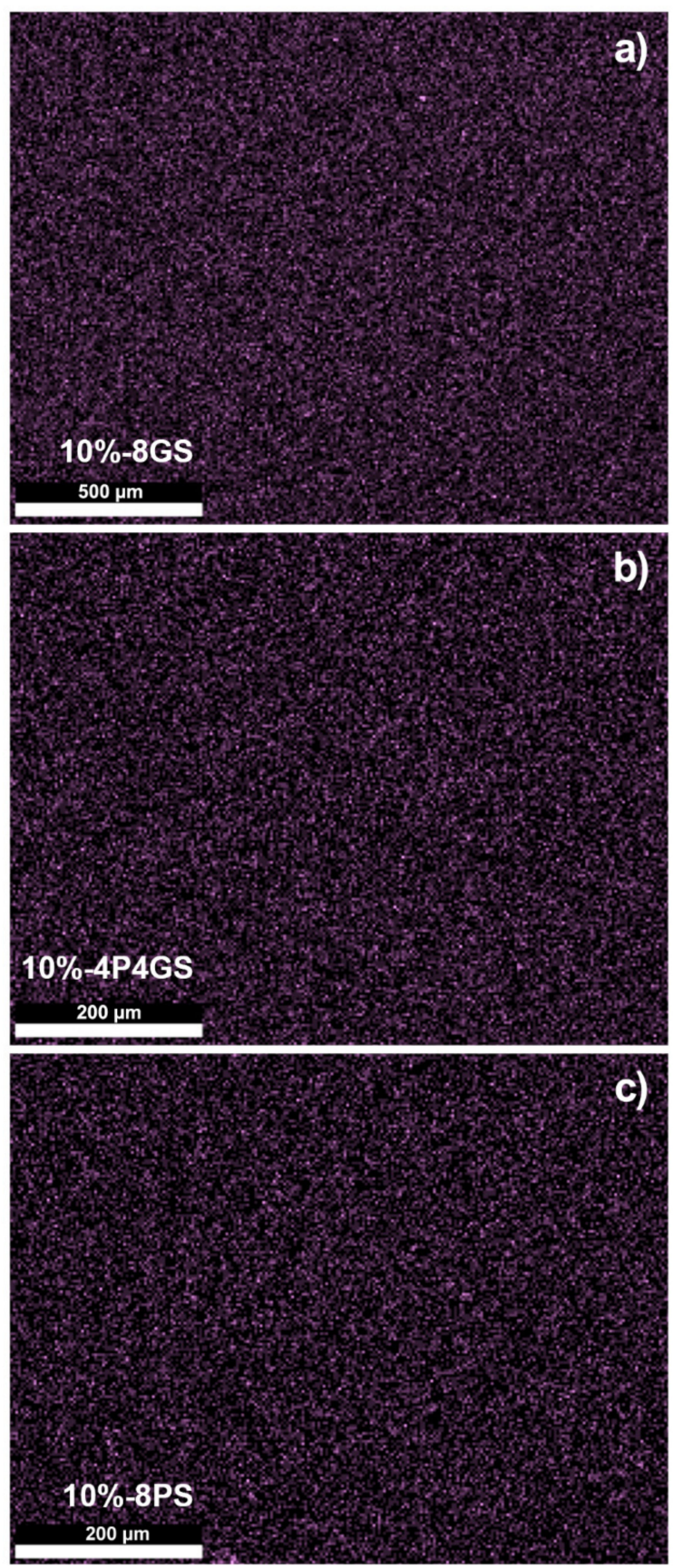

Figure 3. Scanning electron microscopy and energy-dispersive X-ray spectroscopy (SEM-EDS) silicon distribution maps of the modified epoxy resins containing $10 \%$ of (a) 8GS, (b) 4P4GS, and (c) 8PS derivatives.

The results of the silicon and phosphorus concentration measurements that are presented in Table 2 confirm the assumed compositions of the prepared resins. 
Table 2. Calculated and measured weights of Si and P in the prepared samples.

\begin{tabular}{|c|c|c|c|c|c|c|}
\hline \multirow[t]{2}{*}{ Sample } & \multicolumn{2}{|c|}{ Calculated Element Weight (\%) } & \multicolumn{2}{|c|}{$\begin{array}{l}\text { Measured Element Weight } \\
(\%)\end{array}$} & \multicolumn{2}{|c|}{ Error (\%) } \\
\hline & Si & $\mathbf{P}$ & Si & $\mathbf{P}$ & $\mathrm{Si}$ & $\mathbf{P}$ \\
\hline Ref & - & - & - & - & - & - \\
\hline $1 \%-8 \mathrm{GS}$ & 0.15 & - & 0.19 & 0.01 & 7.05 & 55.63 \\
\hline $5 \%-8 \mathrm{GS}$ & 0.74 & - & 0.91 & 0.01 & 3.59 & 56.14 \\
\hline $10 \%-8 \mathrm{GS}$ & 1.42 & - & 1.69 & 0.01 & 3.13 & 55.94 \\
\hline $1 \%-4 \mathrm{P} 4 \mathrm{GS}$ & 0.1 & 0.03 & 0.07 & 0.02 & 18.71 & 54.88 \\
\hline $5 \%-4 \mathrm{P} 4 \mathrm{GS}$ & 0.51 & 0.14 & 0.4 & 0.1 & 4.86 & 12.84 \\
\hline $10 \%-4 \mathrm{P} 4 \mathrm{GS}$ & 0.97 & 0.27 & 0.88 & 0.25 & 3.48 & 6.61 \\
\hline $1 \%-8 \mathrm{PS}$ & 0.08 & 0.04 & 0.12 & 0.07 & 11.79 & 19.81 \\
\hline $5 \%-8 \mathrm{PS}$ & 0.38 & 0.21 & 0.3 & 0.17 & 5.21 & 8.55 \\
\hline $10 \%-8 \mathrm{PS}$ & 0.74 & 0.41 & 0.73 & 0.41 & 3.68 & 4.99 \\
\hline
\end{tabular}

The SEM-EDS micrographs confirming the uniform distribution of the silicon and phosphorous atoms in the other samples can be found in the Supplementary Materials (Figures S17-S46 and Tables S1-S10).

\subsection{Surface Properties}

To assess the effect of the type and amount of the modifier on the surface properties of the prepared samples, the hydrophobicity of their surfaces was determined based on the static WCA. The WCA values obtained for all samples are summarized in Table 3. According to the results, for all samples except $10 \%-8 \mathrm{PS}$, the WCA values were slightly increased, from $77^{\circ}$ for the pure epoxy resin sample to about $80-83^{\circ}$. The decrease in WCA to $50^{\circ}$ observed for the $10 \%-8 \mathrm{PS}$ sample was caused by the highest content of phosphate groups, commonly known as effective surfactants. The obtained results showed that irrespective of the type and amount of the modifier used, their static water contact angles remained below $90^{\circ}$, which, in light of the adopted definitions, classifies them as hydrophilic materials [31].

Table 3. Water contact angles (WCAs) of the modified epoxy resins.

\begin{tabular}{cc}
\hline Sample & WCA $\left({ }^{\circ}\right)$ \\
\hline Ref & $77.1 \pm 3.4$ \\
\hline $1 \%-8 G S$ & $81 \pm 4.69$ \\
\hline $5 \%-8 G S$ & $81.7 \pm 1.93$ \\
\hline $10 \%-8 G S$ & $80.2 \pm 3.9$ \\
\hline $1 \%-4 P 4 G S$ & $82.7 \pm 2.55$ \\
\hline $5 \%-4 P 4 G S$ & $81 \pm 0.97$ \\
\hline $10 \%-4 P 4 G S$ & $81.3 \pm 1.75$ \\
\hline $1 \%-8 P S$ & $82.5 \pm 0.8$ \\
\hline $5 \%-8 P S$ & $79.7 \pm 1.04$ \\
\hline $10 \%-8 P S$ & $50.1 \pm 3.31$ \\
\hline
\end{tabular}

\subsection{Mechanical Properties}

The effect of the type and amount of the silsesquioxane modifier on the modulus of elasticity and hardness of the prepared epoxies were evaluated using nanoindentation, in which the measured parameters were determined based on the continuously recorded indenter load on the sample and its displacement. The recorded load-displacement curves were then analyzed to determine the mentioned parameters (elasticity modulus and hardness) [32]. The main advantage of the discussed 
analytical technique is the possibility of obtaining information on the basic mechanical properties of the tested materials based on the analysis of samples with limited dimensions (coatings, thin layers) or an increased heterogeneity, such as polymer nanocomposites, including those based on epoxy resins [33-36].

The results of the measurements carried out at room temperature are presented in Table 4 . The presented mechanical parameters are the average values from 16 independent measurements made for each sample.

Table 4. Mechanical properties of modified epoxy resins.

\begin{tabular}{ccccc}
\hline \multirow{2}{*}{ Sample } & \multicolumn{2}{c}{ Modulus (500-1500 nm) } & \multicolumn{2}{c}{ Hardness (500-1500 nm) } \\
\cline { 2 - 5 } & Mean (MPa) & Std. Dev. (\%) & Mean (MPa) & Std. Dev. (\%) \\
\hline Ref. & 3064 & 1.6 & 127 & 1.7 \\
\hline 1\%-8GS & 3555 & 1.6 & 163 & 1.7 \\
\hline $5 \%-8 G S$ & 3149 & 1.4 & 136 & 1.7 \\
\hline $10 \%-8 G S$ & 3149 & 0.9 & 137 & 1.2 \\
\hline $1 \%-4 P 4 G S$ & 3071 & 1.2 & 129 & 1.4 \\
\hline $5 \%-4 P 4 G S$ & 3112 & 0.8 & 132 & 1.1 \\
\hline $10 \%-4 P 4 G S$ & 3086 & 1 & 137 & 1.1 \\
\hline $1 \%-8 P S$ & 3127 & 0.6 & 139 & 2.1 \\
\hline $5 \%-8 P S$ & 3210 & 1.8 & 145 & 0.9 \\
\hline $10 \%-8 P S$ & 3230 & 0.7 & &
\end{tabular}

Std. Dev.—standard deviation.

The results revealed that the type and amount of silsesquioxane used for the preparation of the modified epoxy resins had a marginal influence on the measured mechanical parameters. Nevertheless, it can be observed that the modulus of elasticity and hardness of all the prepared modified epoxies were higher than those measured for the reference sample. The lack of differences in hardness and modulus of elasticity between the samples modified with the silsesquioxane derivatives that were capable of chemical incorporation into the resin structure and those without epoxy groups suggests that in the tested materials, the additives used played only the role of a nanofiller and the increase in crosslinking density did not affect the mechanical properties of the produced materials. It should also be noted that the low standard deviation values of the measured parameters (not exceeding 3\%) proved the high homogeneity of prepared resins, which is consistent with the results of the SEM-EDS analysis.

\subsection{TGA and DSC Measurements}

The samples of epoxy resins modified with 1, 5, and $10 \mathrm{wt} . \%$ of all silsesquioxane derivatives were subsequently subjected to TG and DSC analyses to evaluate the effects of the chemical structure of the studied silsesquioxane derivatives and their amount on the thermal properties of investigated hybrid epoxies. The obtained results revealed some quite well-pronounced differences in the TG and DTG (derivative thermogravimetric) curves, confirming the influence of the applied silsesquioxane derivatives on the epoxy resin thermal behavior and the relationship of this behavior to the chemical structures of the derivatives. As the observed changes were the most pronounced for the samples containing the highest amount of modifiers used, only the TG and DTG curves for the samples containing $10 \%$ by weight of $8 \mathrm{GS}, 4 \mathrm{P} 4 \mathrm{GS}$, and $8 \mathrm{PS}$ derivatives are presented. The remaining curves for samples containing 1 and 5\% of the modifiers are presented in Figures S47-S52 available in Supplementary Materials.

The results of the TG and DTG analyses in the $\mathrm{N}_{2}$ atmosphere shown in Figure 4 revealed that all investigated samples decomposed in two distinct steps, taking place in the ranges from 40-270 and 
$270-600{ }^{\circ} \mathrm{C}$. The first of them was most probably the result of the evaporation of benzyl alcohol present in the IDA hardener in the amount of approximately $20 \mathrm{wt} . \%$ and trapped in the prepared samples during the curing process, while the second one was the result of the thermal decomposition of the polymeric network.
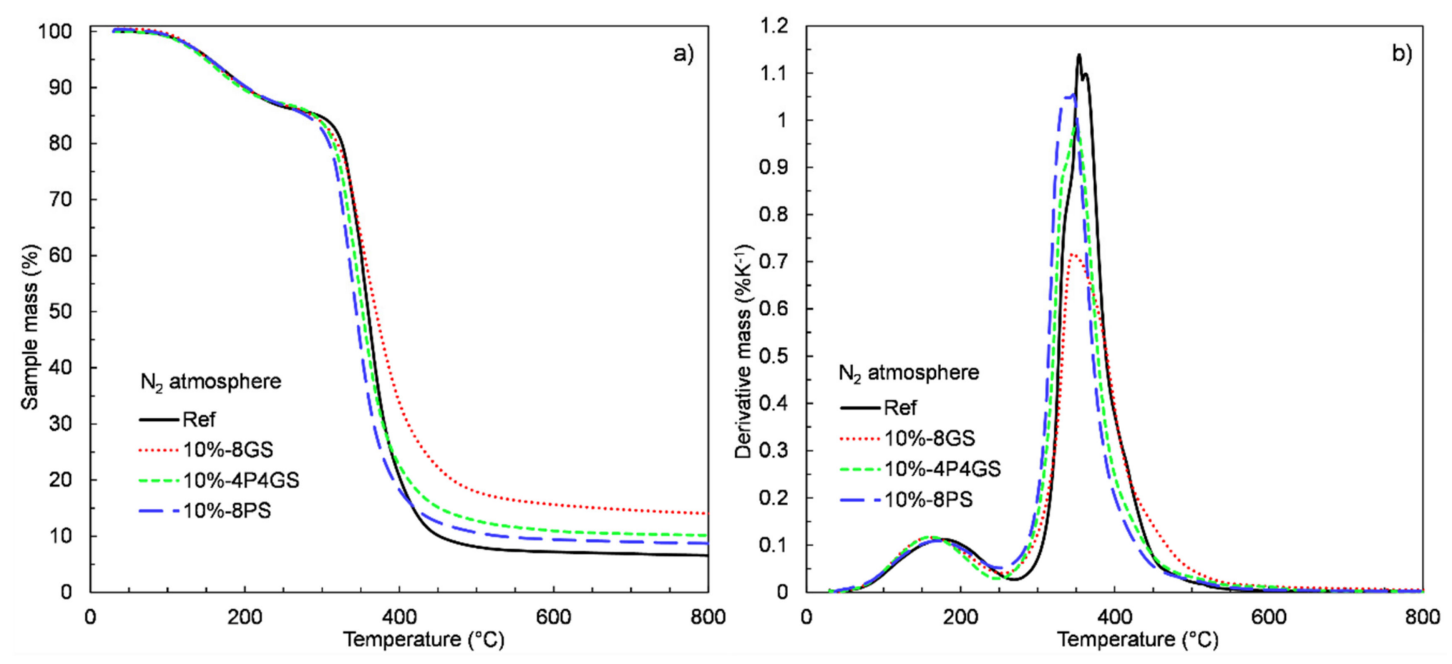

Figure 4. Thermogravimetric TG (a) and derivative thermogravimetric DTG (b) plots for epoxy resins modified with $10 \%$ of the $8 \mathrm{GS}, 4 \mathrm{P} 4 \mathrm{GS}$, and $8 \mathrm{PS}$ derivatives in the $\mathrm{N}_{2}$ atmosphere.

As mentioned above, the influence of a $1 \%$ addition of all the tested silsesquioxane derivatives on the thermal properties of the obtained materials was marginal. More pronounced effects of the applied modifiers were observed for the 5 and $10 \%$ additions. The addition of $5 \%$ of the $8 \mathrm{GS}$ derivative caused a slight increase in the thermal stability of the epoxy resin, but increasing its amount to $10 \%$ by weight caused a slight decrease. Furthermore, in the case of samples containing 5 and $10 \%$ of the 8GS derivative, a decrease in the rate of the decomposition process was observed, which was manifested as a decrease in the maxima of the DTG curves and an increase in the residue at $800{ }^{\circ} \mathrm{C}$. The effect of a decrease of the thermal stability was also observed in the case of samples containing 5 and $10 \%$ of the 4P4GS derivative, and especially the 8PS one. This was evidenced by the shift of the peaks of the second decomposition stage in their DTG curves toward lower temperatures with a simultaneous slight decrease in their height.

The observed effects were directly related to the changes in the structure of the applied modifiers and resulted from the decreased number of reactive epoxy groups present in the applied modifier molecules (from 8 to 4 and 0 ), causing a gradual decrease in the samples' crosslinking density and an increase in the content of phosphate groups, from 0 to 4 and 8 . The detailed results of TG and DTG analyses carried out in the $\mathrm{N}_{2}$ atmosphere are summarized in Tables 5 and 6 . 
Table 5. Results of the TG analysis for epoxy resins modified with 1, 5, and $10 \mathrm{wt}$.\% of silsesquioxane derivatives in the $\mathrm{N}_{2}$ atmosphere.

\begin{tabular}{|c|c|c|c|c|c|c|c|c|}
\hline \multirow{2}{*}{ Sample } & \multicolumn{7}{|c|}{ Mass Loss Temperature $\left({ }^{\circ} \mathrm{C}\right)$} & \multirow{2}{*}{ Char Yield @ $800^{\circ} \mathrm{C}(\%)$} \\
\hline & $\mathrm{T}_{1 \%}$ & $\mathrm{~T}_{5 \%}$ & $\mathbf{T}_{\mathbf{1 0} \%}$ & $\mathrm{~T}_{\mathbf{2 0} \%}$ & $\mathrm{~T}_{40 \%}$ & $T_{60 \%}$ & $\mathbf{T}_{80 \%}$ & \\
\hline Ref. & 104.2 & 155.4 & 201.3 & 325.7 & 350.8 & 368.8 & 401.6 & 6.6 \\
\hline $1 \%-8 \mathrm{GS}$ & 96.7 & 146.8 & 190.3 & 325.4 & 352 & 369.7 & 404.4 & 7.6 \\
\hline $5 \%-8 \mathrm{GS}$ & 100.1 & 143.8 & 189 & 329.1 & 356.3 & 377.7 & 424.9 & 10.9 \\
\hline $10 \%-8 \mathrm{GS}$ & 111 & 153.3 & 199.6 & 320 & 355.1 & 386.6 & 469.2 & 14.1 \\
\hline $1 \%-4 \mathrm{P} 4 \mathrm{GS}$ & 104 & 151.7 & 196 & 326.3 & 351.7 & 368.8 & 401.5 & 6.9 \\
\hline $5 \%-4 \mathrm{P} 4 \mathrm{GS}$ & 105.6 & 152.4 & 198.2 & 318.5 & 344.6 & 364 & 400 & 8 \\
\hline $10 \%-4 \mathrm{P} 4 \mathrm{GS}$ & 101.3 & 149.3 & 194.9 & 315.1 & 342.2 & 363.4 & 412.1 & 10.2 \\
\hline $1 \%-8 \mathrm{PS}$ & 110.7 & 161.4 & 208.9 & 321.8 & 347.6 & 366.9 & 400.2 & 7.2 \\
\hline $5 \%-8 \mathrm{PS}$ & 104.1 & 152.3 & 197.6 & 317.8 & 343.2 & 361.9 & 392.6 & 7.8 \\
\hline $10 \%-8 \mathrm{PS}$ & 106.6 & 154.9 & 202.9 & 309.2 & 334.7 & 353.9 & 392.2 & 8.7 \\
\hline
\end{tabular}

$\mathrm{T}_{1 \%}, \mathrm{~T}_{5 \%}, \mathrm{~T}_{10 \%}, \mathrm{~T}_{20 \%}, \mathrm{~T}_{40 \%}, \mathrm{~T}_{60} \%, \mathrm{~T}_{80 \%}$-temperatures of $1,5,10,20,40,60$ and $80 \%$ mass loss, respectively.

Table 6. Results of the DTG analysis for epoxy resins modified with 1, 5, and $10 \mathrm{wt} . \%$ of silsesquioxane derivatives in the $\mathrm{N}_{2}$ atmosphere.

\begin{tabular}{|c|c|c|c|c|c|c|c|c|}
\hline \multirow{2}{*}{ Sample } & \multicolumn{4}{|c|}{ Step I } & \multicolumn{4}{|c|}{ Step II } \\
\hline & $\begin{array}{c}\text { Range } \\
\left({ }^{\circ} \mathrm{C}\right)\end{array}$ & $\begin{array}{c}\text { Change } \\
(\%)\end{array}$ & $\begin{array}{l}\mathrm{T}_{\max } \\
\left({ }^{\circ} \mathrm{C}\right)\end{array}$ & $\begin{array}{c}\text { Rate } \\
\left(\% K^{-1}\right)\end{array}$ & $\begin{array}{c}\text { Range } \\
\left({ }^{\circ} \mathrm{C}\right)\end{array}$ & $\begin{array}{c}\text { Change } \\
(\%)\end{array}$ & $\begin{array}{l}\mathrm{T}_{\max } \\
\left({ }^{\circ} \mathrm{C}\right)\end{array}$ & $\begin{array}{c}\text { Rate } \\
\left(\% K^{-1}\right)\end{array}$ \\
\hline Ref. & $41-270$ & 14.1 & 176 & 0.11 & $270-600$ & 78.7 & 353.8 & 1.14 \\
\hline 1\%-8GS & $52-260$ & 13.6 & 161.3 & 0.12 & $260-600$ & 77.7 & 362.8 & 1.15 \\
\hline $5 \%-8 \mathrm{GS}$ & $44-255$ & 12.7 & 150.5 & 0.12 & $255-600$ & 75.9 & 361.8 & 0.99 \\
\hline $10 \%-8 \mathrm{GS}$ & $40-255$ & 13.8 & 161.3 & 0.12 & $255-600$ & 71.1 & 345.7 & 0.72 \\
\hline 1\%-4P4GS & $46-263$ & 13.5 & 167.8 & 0.12 & $263-600$ & 79 & 356.7 & 1.26 \\
\hline $5 \%-4 \mathrm{P} 4 \mathrm{GS}$ & $41-260$ & 13.9 & 167.7 & 0.11 & $260-600$ & 77.5 & 354.5 & 1 \\
\hline $10 \%-4 \mathrm{P} 4 \mathrm{GS}$ & $40-250$ & 12.8 & 161.3 & 0.12 & $250-650$ & 76.6 & 349.8 & 1 \\
\hline $1 \%-8 P S$ & $50-270$ & 14.2 & 180.5 & 0.11 & $270-600$ & 78.1 & 359.8 & 1.1 \\
\hline $5 \%-8 P S$ & $45-255$ & 13.2 & 167.2 & 0.12 & $255-600$ & 78.4 & 350.8 & 1.1 \\
\hline $10 \%-8 \mathrm{PS}$ & -250 & 13.7 & 170.2 & 0.11 & $250-600$ & 77.3 & 346.2 & 1.1 \\
\hline
\end{tabular}

The differences in the thermal behavior of the discussed resins are even more pronounced in the case of the TG and DTG curves for samples measured in the air atmosphere shown in Figure 5. 

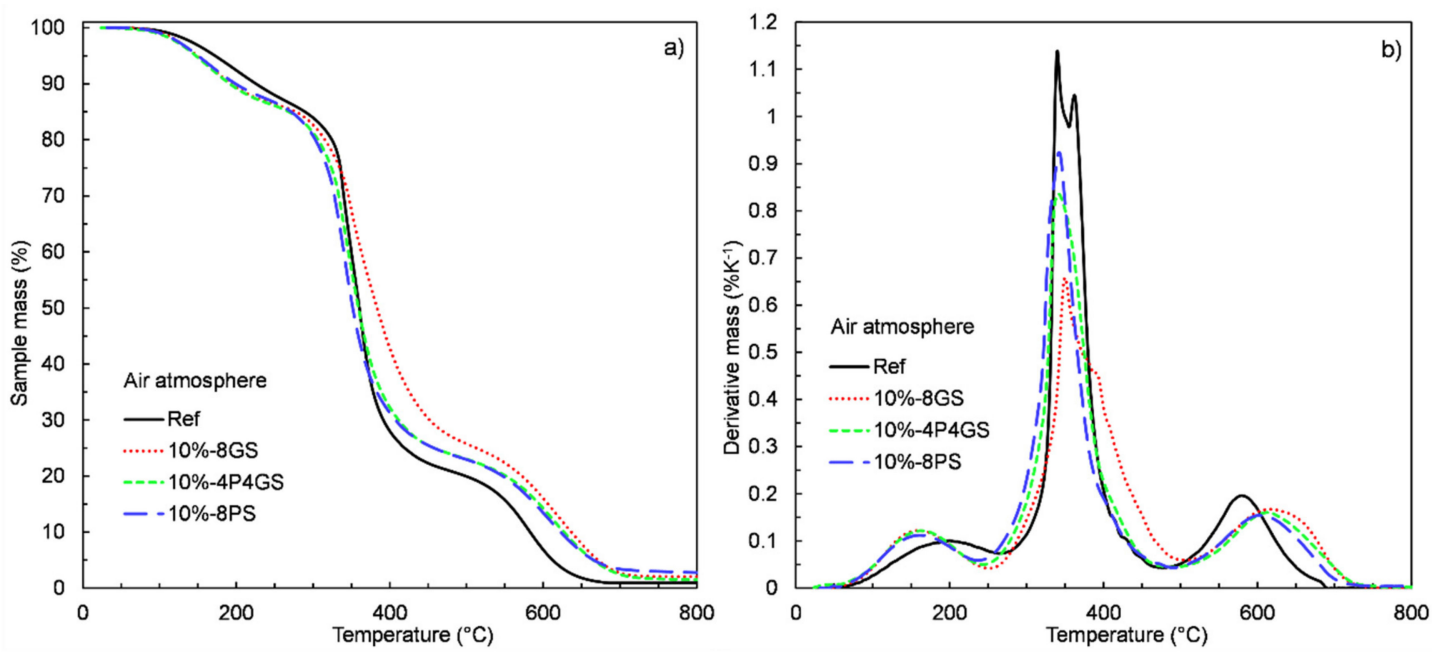

Figure 5. TG (a) and DTG (b) plots for the epoxy resins modified with $10 \%$ of $8 \mathrm{GS}, 4 \mathrm{P} 4 \mathrm{GS}$, and 8PS derivative in the air atmosphere.

While the bimodal decomposition process was observed in the experiments carried out in the $\mathrm{N}_{2}$ atmosphere, an additional decomposition step in the range of $470-750^{\circ} \mathrm{C}$ (depending on the amount and type of modifier used) was observed for all samples measured in the air atmosphere, making the process trimodal. Besides the previously discussed effects of the decrease of the thermal stability of the tested samples and the lowering of their decomposition rate, in the case of experiments conducted in the air atmosphere, the influence of the modifiers used on shifting the third decomposition step of modified resins toward higher temperatures was also observed. This proved that the presence of the discussed derivatives could help to preserve the carbonized protective layer that formed in the second decomposition stage and could protect the materials against high temperatures and restrict the combustion process. The results of TG and DTG analyses for all samples measured in the air atmosphere are summarized in Tables 7 and 8.

Table 7. Results of the TG analysis for epoxy resins modified with 1, 5, and $10 \mathrm{wt}$.\% of silsesquioxane derivatives in the air atmosphere.

\begin{tabular}{|c|c|c|c|c|c|c|c|c|}
\hline \multirow{2}{*}{ Sample } & \multicolumn{7}{|c|}{ Mass Loss Temperature $\left({ }^{\circ} \mathrm{C}\right)$} & \multirow{2}{*}{ Residue @ $800^{\circ} \mathrm{C}(\%)$} \\
\hline & $\mathbf{T}_{\mathbf{1} \%}$ & $\mathrm{~T}_{5 \%}$ & $\mathrm{~T}_{10 \%}$ & $\mathrm{~T}_{20 \%}$ & $\mathrm{~T}_{40 \%}$ & $\mathrm{~T}_{60 \%}$ & $\mathrm{~T}_{\mathbf{8 0} \%}$ & \\
\hline Ref & 113.5 & 171.3 & 222.8 & 318.7 & 343.3 & 363.5 & 490 & 0.96 \\
\hline $1 \%-8 \mathrm{GS}$ & 104.7 & 153.1 & 197.8 & 312.8 & 346.4 & 374.4 & 457 & 0.44 \\
\hline $5 \%-8 \mathrm{GS}$ & 94.7 & 143.2 & 184.3 & 305.8 & 350.7 & 387.1 & 543.9 & 0.59 \\
\hline $10 \%-8 \mathrm{GS}$ & 104.3 & 148.6 & 191.6 & 309.8 & 355.8 & 400 & 561.9 & 2 \\
\hline $1 \%-4 \mathrm{P} 4 \mathrm{GS}$ & 106.1 & 157 & 202.4 & 312.3 & 345 & 369.7 & 431.3 & 0 \\
\hline $5 \%-4 \mathrm{P} 4 \mathrm{GS}$ & 105.2 & 154.4 & 198.3 & 308.1 & 340.4 & 364.4 & 497.8 & 0.8 \\
\hline $10 \%-4 \mathrm{P} 4 \mathrm{GS}$ & 98.8 & 147.5 & 190.3 & 301.3 & 339.6 & 368.7 & 542 & 1.48 \\
\hline $1 \%-8 \mathrm{PS}$ & 109.4 & 158 & 202.7 & 312.3 & 343.9 & 371 & 436.2 & 0.23 \\
\hline $5 \%-8 P S$ & 99 & 147.4 & 190.2 & 300.7 & 337.8 & 359.7 & 501.2 & 0 \\
\hline $10 \%-8 \mathrm{PS}$ & 102.2 & 149.9 & 197.2 & 297.6 & 333.5 & 361.3 & 537.7 & 2.73 \\
\hline
\end{tabular}


Table 8. Results of the DTG analysis for epoxy resins modified with 1, 5, and $10 \mathrm{wt} . \%$ of silsesquioxane derivatives in the air atmosphere.

\begin{tabular}{|c|c|c|c|c|c|c|c|c|c|c|c|c|}
\hline \multirow{2}{*}{ Sample } & \multicolumn{4}{|c|}{ Step I } & \multicolumn{4}{|c|}{ Step II } & \multicolumn{4}{|c|}{ Step III } \\
\hline & $\begin{array}{l}\text { Range } \\
\left({ }^{\circ} \mathrm{C}\right)\end{array}$ & $\begin{array}{l}\text { Change } \\
(\%)\end{array}$ & $\begin{array}{l}T_{\max } \\
\left({ }^{\circ} \mathrm{C}\right)\end{array}$ & $\begin{array}{l}\text { Rate } \\
\left(\% K^{-1}\right)\end{array}$ & $\begin{array}{l}\text { Range } \\
\left({ }^{\circ} \mathrm{C}\right)\end{array}$ & $\begin{array}{l}\text { Change } \\
(\%)\end{array}$ & $\begin{array}{l}T_{\max } \\
\left({ }^{\circ} \mathrm{C}\right)\end{array}$ & $\begin{array}{l}\text { Rate } \\
\left(\% K^{-1}\right)\end{array}$ & $\begin{array}{l}\text { Range } \\
\left({ }^{\circ} \mathrm{C}\right)\end{array}$ & $\begin{array}{l}\text { Change } \\
(\%)\end{array}$ & $\begin{array}{l}T_{\max } \\
\left({ }^{\circ} \mathrm{C}\right)\end{array}$ & $\begin{array}{l}\text { Rate } \\
\left(\% \mathrm{~K}^{-1}\right)\end{array}$ \\
\hline $\mathrm{Re}$ & $55-260$ & 13.4 & 196.8 & 0.1 & $260-470$ & 65.6 & 333.5 & 1.14 & $470-680$ & 20.1 & 569.5 & 0.2 \\
\hline $1 \%-8 \mathrm{GS}$ & -257 & 14 & 169.3 & 0.12 & $257-503$ & 68.6 & 341.5 & 0.9 & $503-738$ & 17 & 587.5 & 0.14 \\
\hline $5 \%-8 \mathrm{GS}$ & $30-246$ & 14.1 & 158 & 0.13 & $246-489$ & 61.7 & 350.5 & 0.67 & $489-733$ & 23.5 & 593.8 & 0.18 \\
\hline $10 \%-8 \mathrm{GS}$ & $30-247$ & 13.7 & 159.3 & 0.12 & $247-498$ & 61 & 343 & 0.66 & $498-746$ & 23.3 & 606.3 & 0.17 \\
\hline $1 \%-4 \mathrm{P} 4 \mathrm{GS}$ & $42-257$ & 14 & 177 & 0.11 & $257-514$ & 72.4 & 348.2 & 0.97 & 514-714 & 13.6 & 600.2 & 0.13 \\
\hline $5 \%-4 \mathrm{P} 4 \mathrm{GS}$ & $41-251$ & 14 & 172.8 & 0.12 & $251-483$ & 65.3 & 336.8 & 1 & $483-734$ & 19.9 & 580.3 & 0.16 \\
\hline $10 \%-4 \mathrm{P} 4 \mathrm{GS}$ & $47-240$ & 13.6 & 162 & 0.12 & $240-483$ & 62.9 & 335.7 & 0.8 & $483-754$ & 21.9 & 604.5 & 0.16 \\
\hline $1 \%-8 \mathrm{PS}$ & $30-255$ & 13.9 & 175.3 & 0.12 & $255-413$ & 71.4 & 335.3 & 0.9 & $513-733$ & 14.5 & 612.3 & 0.13 \\
\hline $5 \%-8 \mathrm{PS}$ & $52-243$ & 13.9 & 164.7 & 0.12 & $243-479$ & 65.1 & 344.7 & 0.96 & $479-743$ & 21 & 589.7 & 0.16 \\
\hline $10 \%-8 \mathrm{PS}$ & $57-233$ & 12.6 & 160.2 & 0.11 & $233-480$ & 64 & 335.3 & 0.92 & $480-736$ & 20.4 & 591.7 & 0.15 \\
\hline
\end{tabular}

Although the results of TG analysis confirmed the effects of the chemical structure and the amount of the discussed silsesquioxanes on the thermal decomposition kinetics of the modified epoxy resins, it is hard to compare the obtained results with those previously reported by other research groups as they are new compounds and have never been tested before, as well as due to the number of factors affecting the thermal stability of modified epoxy composites, such as the type of epoxy resin and hardener used; the amount, type, and the way it interacts with the polymer matrix; the manner of composite preparation (blending or curing process). Nevertheless, by comparing the obtained results to the exemplary research on epoxy resins modified with octasilsesquioxane derivatives with phosphate groups of a similar structure obtained by Liu et al. or Zheng et al., certain regularities can be found [37-40]. The results of the TG analysis presented by the abovementioned research groups, as in the case of the discussed derivatives and the materials obtained with their use, revealed that the addition of DOPO-functionalized silsesquioxane derivatives, especially introduced in an amount exceeding 3.5\%, slightly reduces the temperature of the beginning of the decomposition process of the tested samples, decreases the rate of the first decomposition step and, in the case of measurements carried out in an air atmosphere, increases the temperature of the maximum decomposition rate at its last stage. The addition of DOPO-functionalized octasilsesquioxane derivatives to epoxy resins also causes a slight increase in char yield at $700-800^{\circ} \mathrm{C}$.

Despite the presence of certain analogies, it should be emphasized that the compared studies were conducted with the use of slightly different epoxy resins, other curing agents, and the prepared samples were hardened at different temperatures. Moreover, it should be noted that the derivatives used by Liu et al. and Zheng et al. did not have reactive epoxy groups in their structure that would enable their chemical incorporation into the material's structure. As mentioned above, all these factors make a more precise comparison of the thermal properties of the discussed materials very difficult.

The DSC analysis also revealed slight changes in the course of DSC curves (see Figures S53-S56 in the Supplementary Materials), which was dependent on the type and amount of the modifier. Only the glass transition $\left(\mathrm{T}_{\mathrm{g}}\right)$ manifested as the characteristic, reversible step transition in the heat flow was observed in this case. The glass transition temperatures, determined as the midpoints of the second cooling curves, are collected in Table 9. It can be seen that the addition of $1 \%$ of reactive $8 \mathrm{GS}$ or $4 \mathrm{P} 4 \mathrm{GS}$ caused a slight increase in the $\mathrm{T}_{\mathrm{g}}$ temperature compared to that of the reference sample, while for the sample containing $1 \%$ of $8 \mathrm{PS}$, the $\mathrm{T}_{\mathrm{g}}$ temperature was almost unchanged. The addition of $10 \%$ of all modifiers resulted in a minor decrease in the $\mathrm{T}_{\mathrm{g}}$ temperature. The most significant decrease (by more than $4{ }^{\circ} \mathrm{C}$ ) was observed for the sample containing $10 \%$ of the $8 \mathrm{PS}$ derivative with no reactive epoxy groups. The DSC analysis confirmed the effect of the chemical structure and amount of the silsesquioxanes used on the thermal properties of the modified epoxy resins. 
Table 9. Results of the DSC analysis showing the glass temperature $\left(\mathrm{T}_{\mathrm{g}}\right)$ for epoxy resins modified with 1 and $10 \%$ of the silsesquioxane derivatives.

\begin{tabular}{cc}
\hline Sample & $\mathbf{T}_{\mathbf{g}}\left({ }^{\circ} \mathbf{C}\right)$ \\
\hline Ref. & 43.93 \\
1\%-8GS & 44.44 \\
$10 \%-8 \mathrm{GS}$ & 42.24 \\
$1 \%-4 \mathrm{P} 4 \mathrm{GS}$ & 45.91 \\
$10 \%-4 \mathrm{P} 4 \mathrm{GS}$ & 41.47 \\
1\%-8PS & 43.57 \\
$10 \%-8 \mathrm{PS}$ & 39.88 \\
\hline
\end{tabular}

\subsection{Flammability}

The response of the formulations studied to a simulated fire scenario was evaluated using the measurements taken with a cone calorimeter (CC) [41]. The heat release rate (HRR) curves are presented in Figure 6, while the values of the key parameters for the assessment of the flammability of the tested materials are summarized in Table 10.
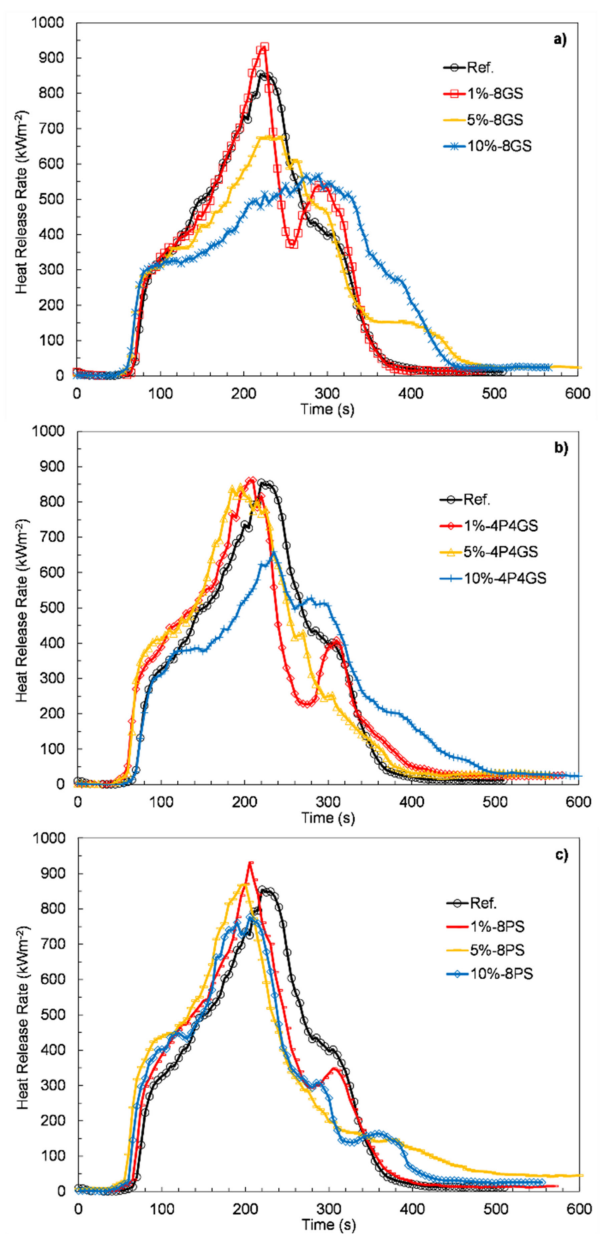

Figure 6. Heat release rate (HRR) curves of the epoxy resin samples modified with (a) 8GS, (b) 4P4GS, and (c) 8PS silsesquioxane. 
Table 10. Cone calorimeter results of epoxy resins with different amounts of silsesquioxanes.

\begin{tabular}{|c|c|c|c|c|c|c|c|c|}
\hline Sample & $\begin{array}{l}\text { TTI } \\
\text { (s) }\end{array}$ & $\begin{array}{l}\text { TTF } \\
\text { (s) }\end{array}$ & $\begin{array}{c}\text { pHRR } \\
\left(\mathbf{k W m} \mathbf{m}^{-2}\right)\end{array}$ & $\begin{array}{l}\text { MARHE } \\
\left(\mathbf{k W m}^{-2}\right)\end{array}$ & $\begin{array}{l}\text { FIGRA } \\
\left(\mathrm{kWm}^{-2} \mathrm{~s}^{-1}\right)\end{array}$ & $\begin{array}{c}\text { THR } \\
\left(\mathrm{MJm}^{-2}\right)\end{array}$ & $\begin{array}{c}\text { SEA } \\
\left(\mathrm{m}^{2} \mathrm{~kg}^{-1}\right)\end{array}$ & $\begin{array}{c}\text { TSR } \\
\left(\mathrm{m}^{2} \mathrm{~m}^{-2}\right)\end{array}$ \\
\hline Ref. & 63 & 393 & 854.5 & 405.9 & 3.9 & 139.4 & 842.2 & 4733.4 \\
\hline 1\%-8GS & 65 & 380 & 932 & 399.2 & 4.1 & 138.2 & 796.7 & 4435 \\
\hline $5 \%-8 G S$ & 56 & 485 & 678.2 & 372.5 & 2.9 & 143.1 & 832.4 & 4844 \\
\hline $10 \%-8 \mathrm{GS}$ & 58 & 455 & 566 & 348.8 & 2.1 & 144.6 & 932.7 & 5538.4 \\
\hline 1\%-4P4GS & 51 & 470 & 861.3 & 412.7 & 4.1 & 141.1 & 822.1 & 4527.6 \\
\hline $5 \%-4 \mathrm{P} 4 \mathrm{GS}$ & 60 & 402 & 845.3 & 436.7 & 4.3 & 143.7 & 755.1 & 4480.1 \\
\hline $10 \%-4 \mathrm{P} 4 \mathrm{GS}$ & 67 & 528 & 658.5 & 349.8 & 2.8 & 143.3 & 833.4 & 4970.4 \\
\hline 1\%-8PS & 60 & 425 & 931.1 & 413.1 & 4.5 & 137.9 & 790.8 & 4309.9 \\
\hline $5 \%-8 \mathrm{PS}$ & 57 & 526 & 869.2 & 430.8 & 4.3 & 153.2 & 830.4 & 4574.1 \\
\hline $10 \%-8 \mathrm{PS}$ & 60 & 438 & 776.6 & 399.7 & 3.8 & 134.9 & 835.6 & 4529.4 \\
\hline
\end{tabular}

TTI: time to ignition, TTF: time to flameout, pHRR: peak heat release rate, MARHE: maximum average rate of the heat emission, FIGRA: fire growth rate, THR: total heat release, SEA: specific extinction area, TSR: total smoke release.

It was found that all samples were ignited after 51-67 s, and the time to ignition (TTI) values did not depend on the presence or amount of the investigated flame retardants (Table 10). As can be seen from Figure 6, the reference unmodified epoxy resin (Ref.) burned intensively with a pHRR of $855 \mathrm{~kW}$ $\mathrm{m}^{-2}$ and left a very small residue (Figure 7).

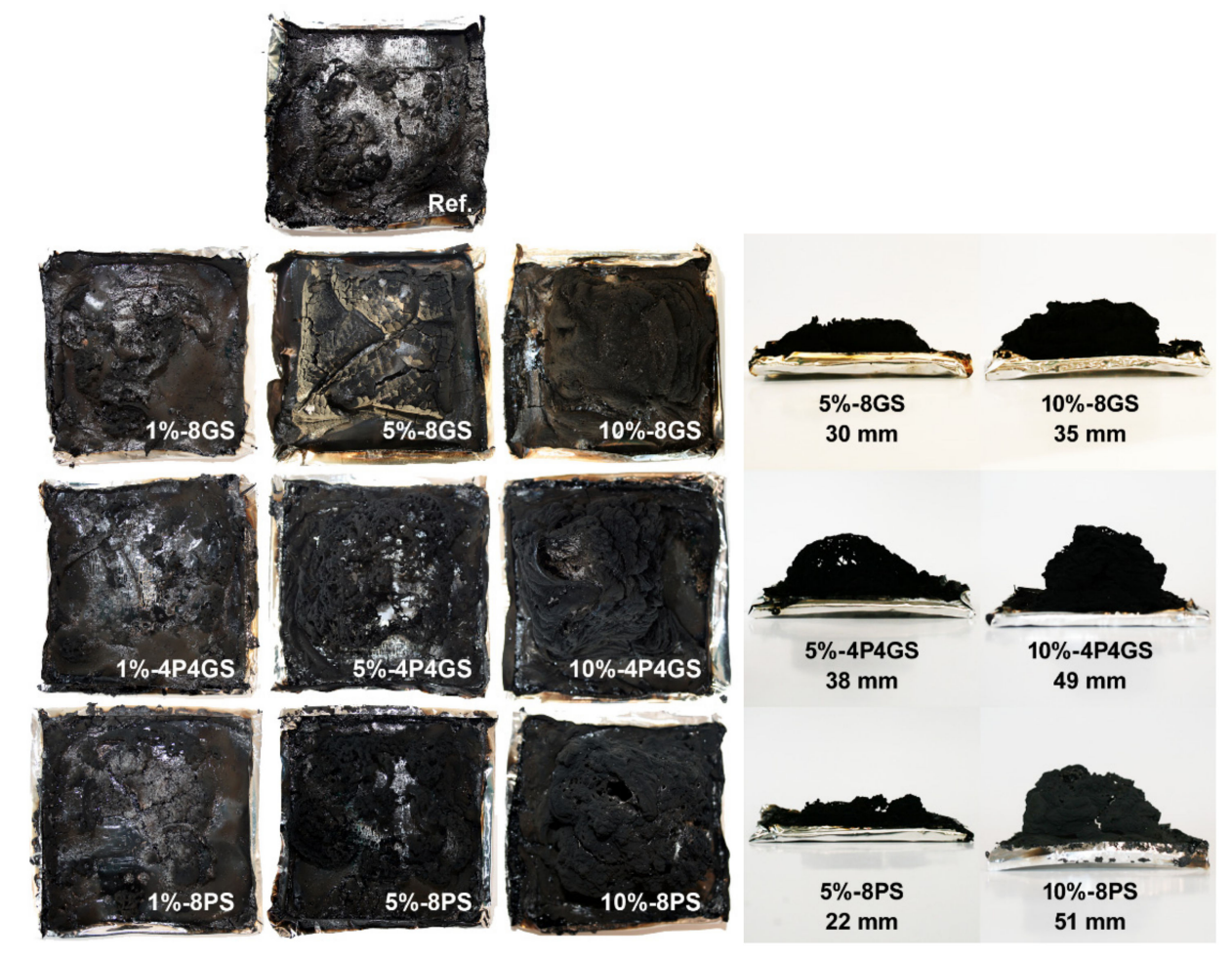

Figure 7. Images of the residue after the cone calorimetry tests (top and side views).

The addition of $1 \mathrm{wt} . \%$ of the functionalized silsesquioxanes did not reduce the HRR; on the contrary, the pHRR values increased, and no change in the amount of residue was observed. The incorporation of $5 \mathrm{wt} . \%$ of the silsesquioxanes led to the formation of carbonaceous char; however, only when $8 \mathrm{GS}$ was added, a significant reduction in pHRR, by approximately $21 \%$, was noted. The image of the 5\%-8GS sample after the cone calorimetry test (Figure 7) shows the swollen structures 
with numerous cracks, while the images of the 5\%-4P4GS and 5\%-8PS reveal a discontinuous mesh-like structure (Figure 7). The lowest pHRR, one-third lower than that of the unmodified resin, was obtained for sample $10 \%-8 \mathrm{GS}$. Only for this material, the char in the form of compact and severely swollen structure, covering most of the sample, was observed. The formation of swollen char prevents heat transmission and enhances the flame retardancy of polymeric materials [42]. The maximum average rate of the heat emission (MARHE), which corresponds to the peak of the cumulative heat emission divided by time, was determined to evaluate the fire development rate.

The values of the MAHRE that were determined for the samples containing 1-10 wt. $\%$ of the 8GS derivative were lower than that of the reference sample, while for the other samples, it was necessary to add at least $10 \mathrm{wt} . \%$ of the modifier to achieve a similar result. Another parameter of great importance that is used to assess the performance of flame retardants is the FIGRA. The values of this parameter were reduced for the samples 5\%-8GS, 10\%-4P4GS, and 10\%-8PS. The lowest MARHE (reduction by $14 \%$ ) and FIGRA (reduction by $46 \%$ ) were determined for the materials labeled as $10 \%-8 \mathrm{GS}$. The total heat release (THR) values were similar, except for sample 5\%-8PS, and ranged from 135 to $143 \mathrm{MJ}$ $\mathrm{m}^{-2}$. The THR was dependent to a certain extent on the flame burning time, and its lowest value was obtained for the samples with the shortest time to flameout (TTF), i.e., for $1 \%-8 \mathrm{GS}, 1 \%-8 \mathrm{PS}$, and $10 \%-8$ PS.

The addition of functionalized silsesquioxanes also had a positive effect on the amount of smoke emitted, which was evaluated based on the specific extinction area (SEA) and the total smoke release (TSR) values, as well as the smoke release rate (SRR) curves presented in Figure 8. As shown in Table 10, the SEA was reduced as a consequence of the addition of the investigated substances. In contrast to the pHRR, the highest values of the SEA were obtained for the sample 10\%-8GS, while the lowest values were found for the samples 1\%-8GS or 1\%-8PS and 5\%-4P4GS. A similar tendency was observed for the TSR, whose highest reduction (by approximately $9 \%$ ) was achieved for $1 \%-8 \mathrm{PS}$.

Analysis of the results allowed us to conclude that while the lowest heat release rate was measured for the epoxy resin with the reactive flame retardant, a greater reduction in smoke emission was noted for the samples modified with an additive flame retardant containing phosphorus groups.

It is to be noted that only small amounts of silsesquioxanes were used to prepare the polymers with reduced flammability and smoke emission; however, it seems reasonable to combine them with intumescent flame retardants to get the enhanced synergy of the individual components, leading to a complete flame retardancy of polymeric materials. 

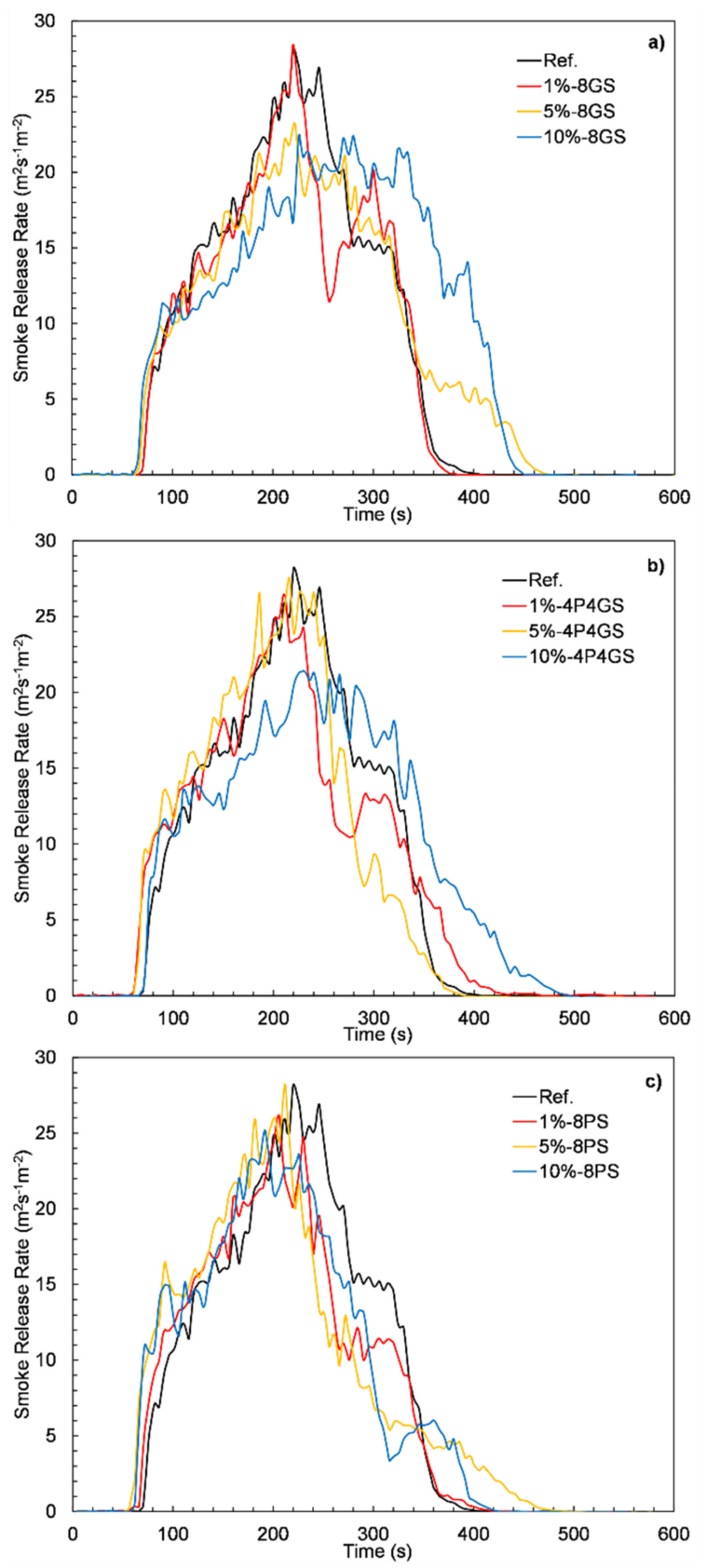

Figure 8. Smoke release rate (SRR) curves of the epoxy resin samples modified with (a) 8GS, (b) 4P4GS, and (c) 8PS silsesquioxane.

\section{Conclusions}

This study aimed to verify the effect of the structure of phosphate cage-like silsesquioxane derivatives and their ability to chemically bond to the polymer matrix on the surface and their mechanical and thermal properties, as well as the flammability of epoxy resins modified with their use. The obtained results show that the chemical structure of the obtained derivatives and their ability to chemically bond to the polymer matrix (epoxy resin) did not significantly affect the elasticity modulus or hardness of the modified materials or their surface properties (hydrophobicity). However, a meaningful impact of the chemical structure of the investigated derivatives on the thermal properties of the resin was observed. The epoxy derivatives that were capable of interacting with the polymer matrix through the formation of covalent bonds were evidenced to cause a notable reduction in 
the thermal decomposition rate of the obtained resins and the shift of the decomposition process toward higher temperatures. The derivatives that were chemically inert toward the modified materials containing only phosphate groups also reduced the rate of decomposition, but its onset was observed at lower temperatures than for pure epoxy resin.

In contrast, the derivatives containing phosphate and epoxy groups that were capable of chemical reactions with the modified resin were responsible for the lowering of the onset temperature of thermal decomposition, a decrease in the rate of decomposition, and its spread over time.

The differences in the structures of the tested silsesquioxane derivatives also had a clear impact on the flammability of epoxy resins modified with their use. Depending on the structure of the modifier used, reductions in the rate and amount of heat released, the rate of flame spread, or the amount of smoke emitted were observed. However, none of the tested derivatives displayed improvement of all measured parameters at once.

It should also be noted that the measured thermal parameters should be assessed through the prism of the content of additives used, whose amount was calculated in terms of the content of silicon and phosphorus atoms, did not exceed 1.7 and $0.8 \%$ by weight, respectively, as estimated by the EDS analysis.

This led to the conclusion that silsesquioxane derivatives can be considered as effective modifiers of thermal properties of epoxy resins; however, the choice of their chemical structure must be dictated by the assumed target parameters of the designed material.

Supplementary Materials: The NMR and FT-IR spectra of the isolated compounds and the results of the SEM-EDS, DSC, and TG analyses are available online at http://www.mdpi.com/1996-1944/13/23/5373/s1. Figure S1: Structures of DOPA and DOPO (from left, respectively). Figure S2: FT-IR spectra of DOPA and DOPO. Figure S3: 1H NMR spectrum of DOPA. Figure S4: 13C NMR spectrum of DOPA. Figure S5: 31P NMR spectrum of DOPA. Figure S6: 1H NMR spectrum of 8GS derivative. Figure S7: 13C NMR spectrum of 8GS derivative. Figure S8: 29Si NMR spectrum of 8GS compound. Figure S9: 1H NMR spectrum of 4P4GS derivative. Figure S10: 13C NMR spectrum of 4P4GS derivative. Figure S11: ${ }^{31} \mathrm{P}$ NMR spectrum of 4P4GS derivative. Figure S12: ${ }^{29} \mathrm{Si}$ NMR spectrum of 4P4GS derivative. Figure S13: ${ }^{1} \mathrm{H}$ NMR spectrum of 8PS derivative. Figure S14: ${ }^{13} \mathrm{C}$ NMR spectrum of 8 PS derivative. Figure S15: ${ }^{31} \mathrm{P}$ NMR spectrum of 8PS derivative. Figure S16: ${ }^{29}$ Si NMR spectrum of 8PS derivative. Figure S17. EDS spectrum of unmodified epoxy resin (Ref.) sample. Figure S18: SEM micrograph of unmodified epoxy resin (Ref.) sample. Figure S19: SEM-EDS (a) carbon, (b) oxygen atoms distribution maps of the unmodified epoxy resin Ref. sample. Figure S20: EDS spectrum of 1\%-8GS sample. Figure S21: SEM micrograph of 1\%-8GS sample. Figure S22: SEM-EDS (a) carbon, (b) oxygen, and (c) silicon atoms distribution maps of 1\%-8GS sample. Figure S23: EDS spectrum of 5\%-8GS sample. Figure S24: SEM micrograph of 5\%-8GS sample. Figure S25: SEM-EDS (a) carbon, (b) oxygen, and (c) silicon atoms distribution maps of 5\%-8GS sample. Figure S26: EDS spectrum of 10\%-8GS sample. Figure S27: SEM micrograph of 10\%-8GS sample. Figure S28. SEM-EDS (a) carbon, (b) oxygen, and (c) silicon atoms distribution maps of 10\%-8GS sample. Figure S29: EDS spectrum of 1\%-4P4GS sample. Figure S30: SEM micrograph of 1\%-4P4GS sample. Figure S31. SEM-EDS (a) carbon, (b) oxygen, (c) silicon and(d) phosphorus atoms distribution maps of 1\%-4P4GS sample. Figure S32: EDS spectrum of 5\%-4P4GS sample. Figure S33: SEM micrograph of 5\%-4P4GS sample. Figure S34: SEM-EDS (a) carbon, (b) oxygen, (c) silicon and (d) phosphorus atoms distribution maps of 5\%-4P4GS sample. Figure S35: EDS spectrum of 10\%-4P4GS sample. Figure S36: SEM micrograph of 10\%-4P4GS sample. Figure S37: SEM-EDS (a) carbon, (b) oxygen, (c) silicon and (d) phosphorus atoms distribution maps of 10\%-4P4GS sample. Figure S38: EDS spectrum of 1\%-8PS sample. Figure S39: SEM micrograph of 1\%-8PS sample. Figure S40: SEM-EDS (a) carbon, (b) oxygen, (c) silicon and (d) phosphorus atoms distribution maps of 1\%-PS sample. Figure S41: EDS spectrum of 5\%-8PS sample. Figure S42: SEM micrograph of 5\%-8PS sample. Figure S43. SEM-EDS (a) carbon, (b) oxygen, (c) silicon and (d) phosphorus atoms distribution maps of 5\%-PS sample. Figure S44: EDS spectrum of 10\%-8PS sample. Figure S45: SEM micrograph of 10\%-8PS sample. Figure S46: SEM-EDS (a) carbon, (b) oxygen, (c) silicon and (d) phosphorus atoms distribution maps of 10\%-PS sample. Figure S47: Graphs of (a) TG and (b) DTG curves of epoxy resin samples modified with 1,5 and 10\%wt. of 8GS derivative in N2 atmosphere. Figure S48: Graphs of (a) TG and (b) DTG curves of epoxy resin samples modified with 1,5 and 10\% wt. of 8GS derivative in air atmosphere. Figure S49: Graphs of a) TG and (b) DTG curves of epoxy resin samples modified with 1,5 and 10\% wt. of 4P4GS derivative in N2 atmosphere. Figure S50: Graphs of (a) TG and (b) DTG curves of epoxy resin samples modified with 1, 5 and $10 \%$ of 4 P4GS derivative in air atmosphere. Figure S51: Graphs of (a) TG and (b) DTG curves of epoxy resin samples modified with 1,5 and 10\% wt. of 8PS derivative in N2 atmosphere. Figure S52: Graphs of (a) TG and (b) DTG curves of epoxy resin samples modified with 1,5 and 10\% wt. of 8PS derivative in air atmosphere. Figure S53: DSC heating curves for epoxy resins modified with 1\%wt. of 8GS, 4P4GS and 8PS derivatives. Figure S54: DSC cooling curves for epoxy resins modified with 1\%wt. of 8GS, 4P4GS and 8PS derivatives. Figure S55: DSC heating curves for epoxy resins modified with $10 \%$ wt. of $8 \mathrm{GS}, 4 \mathrm{P} 4 \mathrm{GS}$ and 8PS derivatives. Figure S56: DSC cooling curves for epoxy resins modified with 10\%wt. of 8GS, 4P4GS and 8PS derivatives. Table S1: Results 
of EDS analysis of unmodified epoxy resin (Ref.) sample. Table S2: Results of EDS analysis of 1\%-8GS sample. Table S3: Results of EDS analysis of 5\%-8GS sample. Table S4. Results of EDS analysis of 10\%-8GS sample. Table S5: Results of EDS analysis of 1\%-4P4GS sample. Table S6: Results of EDS analysis of 5\%-4P4GS sample. Table S7: Results of EDS analysis of 10\%-4P4GS sample. Table S8. Results of EDS analysis of 1\%-PS sample. Table S9: Results of EDS analysis of 5\%-PS sample. Table S10: Results of EDS analysis of 10\%-PS sample.

Author Contributions: All authors contributed to the study conception and design. Material preparation, data collection, and analysis were performed by M.S., M.D., M.N., K.S., and M.C. The first draft of the manuscript was written by M.S., M.D., K.S., and B.M. All authors commented on previous versions of the manuscript. All authors have read and agreed to the published version of the manuscript.

Funding: This research was funded by The National Science Centre, Poland, through grant number UMO-2017/27/B/ST5/00149.

Conflicts of Interest: The authors declare no conflict of interest.

\section{References}

1. Hodgkin, J. Thermosets: Epoxies and Polyesters in Encyclopedia of Materials: Science and Technology, 2nd ed.; Buschow, K.H.J., Flemings, M.C., Kramer, E.J., Veyssière, P., Cahn, R.W., Ilschner, B., Mahajan, S., Eds.; Pergamon: Oxford, UK, 2001; pp. 9215-9221. [CrossRef]

2. Hodd, K. 37_Epoxy Resins in Comprehensive Polymer Science and Supplements, 1st ed.; Allen, G., Bevington, J.C., Eds.; Pergamon: Oxford, UK, 1989; Volume 5, pp. 667-699. [CrossRef]

3. Wetzel, B.; Rosso, P.; Haupert, F.; Friedrich, K. Epoxy nanocomposites-Fracture and toughening mechanisms. Eng. Fract. Mech. 2006, 73, 2375-2398. [CrossRef]

4. Jin, F.-L.; Li, X.; Park, S.J. Synthesis and application of epoxy resins: A review. J. Ind. Eng. Chem. 2015, 29, 1-11. [CrossRef]

5. Domun, N.; Hadavinia, H.; Zhang, T.; Sainsbury, T.; Liaghat, G.H.; Vahid, S. Improving the fracture toughness and the strength of epoxy using nanomaterials-a review of the current status. Nanoscale 2015, 7, 10294-10329. [CrossRef] [PubMed]

6. Ramezanzadeh, B.; Niroumandrad, S.; Ahmadi, A.; Mahdavian, M.; Mohamadzadeh Moghadam, M.H. Enhancement of barrier and corrosion protection performance of an epoxy coating through wet transfer of amino functionalized graphene oxide. Corros. Sci. 2016, 103, 283-304. [CrossRef]

7. Ren, H.; Huang, W.; Yang, D. Preparation and investigation of novel diatomite-supported epoxy resin-modified asphalt binder. J. Test. Eval. 2019, 48, 20180399. [CrossRef]

8. Adesina, A.Y.; Zainelabdeen, I.H.; Dalhat, M.A.; Mohammed, A.S.; Sorour, A.A.; Al-Badour, F.A. Influence of micronized waste tire rubber on the mechanical and tribological properties of epoxy composite coatings. Tribol. Int. 2020, 146, 106244. [CrossRef]

9. Gu, J.; Liang, C.; Zhao, X.; Gan, B.; Qiu, H.; Guo, Y.; Yang, X.; Zhang, Q.; Wang, D.-Y. Highly thermally conductive flame-retardant epoxy nanocomposites with reduced ignitability and excellent electrical conductivities. Compos. Sci. Technol. 2017, 139, 83-89. [CrossRef]

10. Wang, X.; Hu, Y.; Song, L.; Xing, W.; Lu, H.; Lv, P.; Jie, G. Flame retardancy and thermal degradation mechanism of epoxy resin composites based on a DOPO substituted organophosphorus oligomer. Polymer 2010, 51, 2435-2445. [CrossRef]

11. Rakotomalala, M.; Wagner, S.; Döring, M. Recent developments in halogen free flame retardants for epoxy resins for electrical and electronic applications. Materials 2010, 3, 4300-4327. [CrossRef]

12. Goodman, S.H. (Ed.) Epoxy Resins in Handbook of Thermoset Plastics, 2nd ed.; William Andrew: Norwich, NY, USA, 1998; pp. 193-268. [CrossRef]

13. Xu, M.-J.; Xu, G.-R.; Leng, Y.; Li, B. Synthesis of a novel flame retardant based on cyclotriphosphazene and DOPO groups and its application in epoxy resins. Polym. Degrad. Stab. 2016, 123, 105-114. [CrossRef]

14. Schartel, B.; Perret, B.; Dittrich, B.; Ciesielski, M.; Kramer, J.; Muller, P.; Altstadt, V.; Zang, L.; Doring, M. Flame Retardancy of Polymers: The Role of Specific Reactions in the Condensed Phase. Macromol. Mater. Eng. 2016, 301, 9-35. [CrossRef]

15. Laoutid, F.; Bonnaud, L.; Alexandre, M.; Lopez-Cuesta, J.-M.; Dubois, P. New prospects in flame retardant polymer materials: From fundamentals to nanocomposites. Mater. Sci. Eng. R Rep. 2009, 63, 100-125. [CrossRef] 
16. Lu, S.-Y.; Hamerton, I. Recent developments in the chemistry of halogen-free flame retardant polymers. Prog. Polym. Sci. 2002, 27, 1661-1712. [CrossRef]

17. Choi, J.; Harcup, J.; Yee, A.F.; Zhu, Q.; Laine, R.M. Organic/inorganic hybrid composites from cubic silsesquioxanes. J. Am. Chem. Soc. 2001, 123, 11420-11430. [CrossRef] [PubMed]

18. Byczyński, Ł.; Dutkiewicz, M.; Januszewski, R. Thermal behaviour and flame retardancy of polyurethane high-solid coatings modified with hexakis(2,3-epoxypropyl)cyclotriphosphazene. Prog. Org. Coat. 2017, 108, 51-58. [CrossRef]

19. Dutkiewicz, M.; Szołyga, M.; Maciejewski, H.; Marciniec, B. Thiirane functional spherosilicate as epoxy resin modifier: Synthesis and thermal stability. J. Therm. Anal. Calorim. 2014, 117, 259-264. [CrossRef]

20. Lin, C.H.; Wu, C.Y.; Wang, C.S. Synthesis and properties of phosphorus-containing advanced epoxy resins. II. J. Appl. Polym. Sci. 2000, 78, 228-235. [CrossRef]

21. van der Veen, I.; de Boer, J. Phosphorus flame retardants: Properties, production, environmental occurrence, toxicity and analysis. Chemosphere 2012, 88, 1119-1153. [CrossRef]

22. Levchik, S.V.; Weil, E.D. Thermal decomposition, combustion and flame-retardancy of epoxy resins-A review of the recent literature. Polym. Int. 2004, 53, 1901-1929. [CrossRef]

23. Shi, Y.; Yu, B.; Zheng, Y.; Guo, J.; Chen, B.; Pan, Z.; Hu, Y. A combination of POSS and polyphosphazene for reducing fire hazards of epoxy resin. Polym. Adv. Technol. 2018, 29, 1242-1254. [CrossRef]

24. Cakmakci, E. Allylamino diphenylphosphine oxide and POSS containing flameretardant photocured hybrid coatings. Prog. Org. Coat. 2017, 105, 37-47. [CrossRef]

25. Zhang, W.; Li, X.; Yang, R. Pyrolysis and fire behaviour of epoxy resin composites based on a phosphorus-containing polyhedral oligomeric silsesquioxane (DOPO-POSS). Polym. Degrad. Stab. 2011, 96, 1821-1832. [CrossRef]

26. Zhang, W.; He, X.; Song, T.; Jiao, Q.; Yang, R. The influence of the phosphorus-based flame retardant on the flame retardancy of the epoxy resins. Polym. Degrad. Stab. 2014, 109, 209-217. [CrossRef]

27. Wang, X.; Hu, Y.; Song, L.; Xing, W.; Lu, H. Thermal degradation behaviors of epoxy resin/poss hybrids and phosphorus-silicon synergism of flame retardancy. J. Polym. Sci. Part. B: Polym. Phys. 2010, 48, 693-705. [CrossRef]

28. Yu, L.; Chen, L.; Dong, L.-P.; Li, L.-J.; Wang, Y.-Z. Organic-inorganic hybrid flame retardant: Preparation, characterization and application in EVA. Rsc Adv. 2014, 4, 17812-17821. [CrossRef]

29. Walczak, M.; Franczyk, A.; Dutkiewicz, M.; Marciniec, B. Synthesis of Bifunctional Silsesquioxanes $\left(\mathrm{RSiMe}_{2} \mathrm{O}\right)_{\sim 4}\left(\mathrm{R}^{\prime} \mathrm{SiMe}_{2} \mathrm{O}\right)_{\sim 4} \mathrm{Si}_{8} \mathrm{O}_{12}$ via Hydrosilylation of Alkenes. Organometallics 2019, 38, 3018-3024. [CrossRef]

30. Walczak, M.; Januszewski, R.; Dutkiewicz, M.; Franczyk, A.; Marciniec, B. A facile approach for the synthesis of novel silsesquioxanes with mixed functional groups. New J. Chem. 2019, 43, 18141-18145. [CrossRef]

31. Law, K.-Y. Definitions for Hydrophilicity, Hydrophobicity, and Superhydrophobicity: Getting the Basics Right. J. Phys. Chem. Lett. 2014, 5, 686-688. [CrossRef]

32. Baker, S.P.; Liu, J. Nanoindentation Techniques in Encyclopedia of Materials: Science and Technology, 2nd ed.; Buschow, K.H.J., Flemings, M.C., Kramer, E.J., Veyssière, P., Cahn, R.W., Ilschner, B., Mahajan, S., Eds.; Pergamon: Oxford, UK, 2001; pp. 5908-5915. [CrossRef]

33. Díez-Pascual, A.M.; Gómez-Fatou, M.A.; Ania, F.; Flores, A. Nanoindentation in polymer nanocomposites. Prog. Mater. Sci. 2015, 67, 1-94. [CrossRef]

34. Van Landingham, M.R.; Villarrubia, J.S.; Guthrie, W.F.; Meyers, G.F. Nanoindentation of Polymers: An Overview. Macromol. Symp. 2001, 167, 15-43. [CrossRef]

35. Beake, B.D.; Harris, A.J.; Liskiewicz, T.W. Advanced nanomechanical test techniques. In Materials Characterization Modern Methods and Applications; Ranganathan, N., Ed.; Jenny Stanford Publishing: Beijing, China, 2016; pp. 1-89. [CrossRef]

36. Zapico, G.F.; Ohtake, N.; Akasaka, H.; Munoz-Guijosa, J.M. Epoxy toughening through high pressure and shear rate preprocessing. Sci. Rep. 2019, 9, 1-9. [CrossRef] [PubMed]

37. Liu, C.; Chen, T.; Yuan, C.; Chang, Y.; Chen, G.; Zeng, B.; Xu, Y.; Luo, W.; Dai, L. Highly transparent and flame-retardant epoxy composites based on a hybrid multi-element containing POSS derivative. Rsc Adv. 2017, 7, 46139-46147. [CrossRef] 
38. Liu, C.; Chen, T.; Yuan, C.H.; Song, C.F.; Chang, Y.; Chen, G.R.; Xu, Y.T.; Dai, L.Z. Modification of epoxy resin through the self-assembly of a surfactant-like multi-element flame retardant. J. Mater. Chem. A 2016, 4, 3462-3470. [CrossRef]

39. Zhang, W.; Li, X.; Yang, R. Novel flame retardancy effects of DOPO-POSS on epoxy resins. Polym. Degrad. Stab. 2011, 96, 2167-2173. [CrossRef]

40. Zhang, W.; Li, X.; Yang, R. Blowing-out effect in epoxy composites flame retarded by DOPO-POSS and its correlation with amide curing agents. Polym. Degrad. Stab. 2012, 97, 1314-1324. [CrossRef]

41. Naik, A.D.; Fontaine, G.; Samyn, F.; Delva, X.; Louisy, J.; Bellayer, S.; Bourgeois, Y.; Bourbigot, S. Outlining the mechanism of flame retardancy in polyamide 66 blended with melamine-poly(zinc phosphate). Fire Saf. J. 2014, 70, 46-60. [CrossRef]

42. Li, Y.; Li, B.; Dai, J.; Jia, H.; Gao, S. Synergistic effects of lanthanum oxide on a novel intumescent flame retardant polypropylene system. Polymer Degrad. Stab. 2008, 93, 9-16. [CrossRef]

Publisher's Note: MDPI stays neutral with regard to jurisdictional claims in published maps and institutional affiliations.

(C) 2020 by the authors. Licensee MDPI, Basel, Switzerland. This article is an open access article distributed under the terms and conditions of the Creative Commons Attribution (CC BY) license (http://creativecommons.org/licenses/by/4.0/). 